Supporting Information

\title{
Bioinorganic Hybrid Non-Genetically Modified Viruses as an Immune Agonist for Systemic Elimination of Cancer Cells
}

Bin Zheng, ${ }^{\text {a, } 1}$ Yanan Xu, b, 1 Mengqian Huang, ${ }^{b}$ Xianhuang Li, b Tao Wang, ${ }^{b, *}$ and Dong Ming a, *

${ }^{a}$ Academy of Medical Engineering and Translational Medicine, Tianjin University, 92 Weijin Road, Nankai District, Tianjin 300072, China.

b School of Life Sciences, Tianjin University, 92 Weijin Road, Nankai District, Tianjin 300072, China.

${ }^{*}$ Corresponding authors.

E-mail addresses: wangtaobio@tju.edu.cn (T. Wang), richardming@tju.edu.cn (D. Ming).

${ }^{1}$ These authors contributed equally to this work. 


\section{Materials and Method}

Materials. The Sendai virus (SEV) BB1 strain was donated by Researcher Lishu Zheng from Chinese Center for Disease Control and Prevention (China, CDC). ICG was purchased from Sigma Aldrich (USA). $\mathrm{CaCl}_{2}$ and $\mathrm{Na}_{2} \mathrm{HPO}_{4}$ were purchased from Aladdin (China). The PE antimouse CD45 antibody, FITC anti-mouse CD80 antibody, APC anti-mouse CD83 antibody, APC anti-mouse CD11c antibody, FITC anti-mouse CD103 antibody, Alexa Fluor ${ }^{\circledR} 488$ anti-mouse CD3 antibody, APC anti-mouse CD4 antibody, APC anti-mouse CD8a antibody, PE anti-mouse FOXP3 antibody, FITC anti-mouse Ly-6G/Ly-6C (Gr-1) were purchased from Biolegend (USA). The ELISA kit against IFN- $\gamma /$ TNF- $\alpha /$ IL-6 from Komabiotech (Seoul, Korea).

Synthesis of nanocomposites: Supervirus ((SEV+ICG)@ $\left.\mathrm{CaHPO}_{4}\right)$ nanocomposites were prepared at room temperature by a simple method. Briefly, mixed SEV virus particles of $1 \times 10^{4}$, $1 \mathrm{mg} / \mathrm{ml} \mathrm{ICG}$ and $12.5 \mathrm{mM} \mathrm{CaCl}_{2}$, stirred at room temperature for $15 \mathrm{~min}$ in the dark. The virus nanoparticles adsorbed with ICG and $\mathrm{Ca}^{2+}$ were centrifuged at high speed for removel free ICG and $\mathrm{Ca}^{2+}$, and then added $2.5 \mathrm{mM} \mathrm{Na}_{2} \mathrm{HPO}_{4}$ dropwise, stired for $30 \mathrm{~min}$ at room temperature, centrifuged at 10,000 rpm for $3 \mathrm{~min}$, and washed with $\mathrm{ddH}_{2} \mathrm{O}$ for later use.

Material characterization: The size and morphology of (SEV+ICG)@CaHPO $\mathrm{Canocomposite}_{4}$ were characterized by transmission electron microscopy (TEM) (Hitachi HT7700); Fluorescence spectra and absorption spectra of ICG, ICG@ $\mathrm{CaHPO}_{4}, \quad \mathrm{SEV} @ \mathrm{CaHPO}_{4}$ and $(\mathrm{SEV}+\mathrm{ICG}) @ \mathrm{CaHPO}_{4}$ were measured by EnSpire Multilabel Reader. The hydrodynamic diameter of supervirus was measured by dynamic light scattering by Nano ZS90. Fluorescence was detected by in vivo imaging system for small animals (IVIS SPECTRUM).

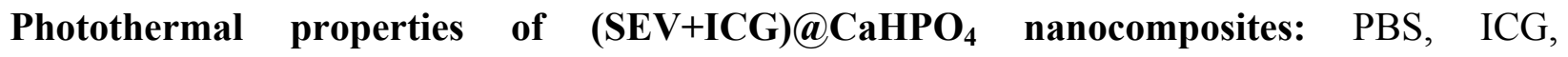
ICG@ $\mathrm{CaHPO}_{4}, \mathrm{SEV} @ \mathrm{CaHPO}_{4}$ and $(\mathrm{SEV}+\mathrm{ICG}) @ \mathrm{CaHPO}_{4}$ were irradiated with 808 nm laser $\left(1.0 \mathrm{~W} \mathrm{~cm}^{-2}\right)$ for 10 minutes, respectively. Temperature changes in each solution were recorded by inserting thermocouple probes. To ensure a uniform heat distribution during laser irradiation, the solution was always stirred magnetically. During the heating of each sample solution, IR thermal images were recorded by thermal imager.

Cell culture: Dendritic cells 2.4 (Immature immune cells) (DC 2.4) were kindly provided by 
Professor Shao-Kai Sun from Tianjin Medical University (China). Macrophages (RAW 264.7) and 4T1 cells (mouse breast cancer cells) were from ATCC. DC 2.4, RAW 264.7 and 4T1 cells were periodically cultured in DMEM (Gibco, USA) and RPMI-1640 (Hyclone, USA), supplemented with 10\% FBS (Bailing Biological, Tianjin, China) and 1\% penicillinstreptomycin (Hyclone USA) in $5 \% \mathrm{CO}_{2}$ at $37{ }^{\circ} \mathrm{C}$.

Dual-Luciferase Reporter Assay: HEK293T (Human Embryonic Kidney 293T) cells were

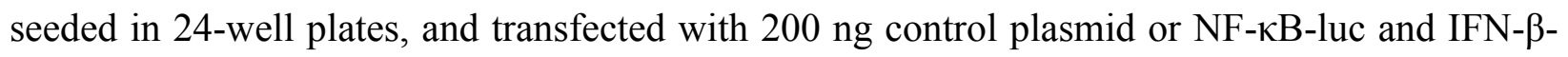
luc reporter plasmids and $1 \mathrm{ng}$ pRL-SV40 plasmids per well or along with the indicated amounts of the expression plasmids using lipofectamine 2000 (Invitrogen). The total DNA amount was kept by empty plasmid. At $24 \mathrm{~h}$ post transfection, cells were treated with different samples and continue to culture for a further $16 \mathrm{~h}$. Cells were harvested and lysed with passive lysis buffer. Luciferase activities in supernatant were measured using a Dual-Luciferase Reporter Assay System (Promega) according to the manufacturer's instructions. Firefly luciferase activity was normalized to Renilla luciferase activity.

In vitro cytotoxicity of $(\mathrm{SEV}+\mathrm{ICG}) @ \mathrm{CaHPO}_{4}$ nanocomplex: The cytotoxicity of the nanocomplex was measured by the DC 2.4 and 4T1 cell line by standard MTT assay (Solarbio, M1020). The log phase cells were collected and the cell suspension concentration was adjusted and divided into 96 -well plates at $100 \mu \mathrm{L}$ per well at 60,000 cells/well. The cells were cultured in a $37{ }^{\circ} \mathrm{C}, 5 \% \quad \mathrm{CO}_{2}$ incubator and cultured for 24 hours. Different concentrations of (SEV+ICG)@CaHPO 4 nanocomposite (0-1000 mg L-1) were added and incubation was continued for $12 \mathrm{~h}$. The supernatant was carefully aspirated, $90 \mu \mathrm{L}$ of fresh medium was added, and $10 \mu \mathrm{L}$ of MTT solution was added to continue the culture for $4 \mathrm{~h}$. Then, the supernatant was aspirated, and $100 \mu \mathrm{L}$ of Formazan solution was added to each well, and shaken at a low speed for 10 min on a shaker to fully dissolve the crystals. The absorbance of each well was measured at $450 \mathrm{~nm}$ at a Multi-function microplate reader (Acer). The cell viability of DC 2.4 and $4 \mathrm{~T} 1$ cells was then calculated.

Endocytosis: In order to verify whether the nanocomplex enters DC 2.4 cells, PBS, $\mathrm{ICG} @ \mathrm{CaHPO}_{4}, \mathrm{SEV} @ \mathrm{CaHPO}_{4}$ and $(\mathrm{SEV}+\mathrm{ICG}) @ \mathrm{CaHPO}_{4}$ nanocomposites were incubated with DC 2.4 cells for $4 \mathrm{~h}$, the cells were washed with phosphate buffer solution (PBS), and fixed 
in 4\% paraformaldehyde solution for $15 \mathrm{~min}$. Then washed thoroughly in PBS. It was permeated with $0.1 \%$ Trition X-100 for $10 \mathrm{~min}$ and washed again in PBS. Cells were stained with $50 \mathrm{mg} / \mathrm{ml}$ fluorescent phalloidin conjugate solution (containing 1\% DMSO from the original stock solution) for $40 \mathrm{~min}$ at room temperature. The unbound phalloidin conjugate was removed by washing several times with PBS. The cells were stained with 4, 6-diamino-2phenylhydrazine hydrochloride (DAPI, Solarbio Life Sciences, Beijing, China) for $10 \mathrm{~min}$ at room temperature. The observation was then carried out using a laser confocal microscope (PerkingElmer, UltraView Vox).

Cytokine measurement: The cytokine secreted by immune cells after stimulation was measured. After $48 \mathrm{~h}$, a suspension of DC 2.4 cell and RAW 264.7 cells culture medium stimulated with SEV@CaHPO 4 , ICG@ $\mathrm{CaHPO}_{4}$ and (SEV+ICG)@CaHPO ${ }_{4}$ was collected and diluted to the appropriate concentration for further analysis. The specific anti-mouse TNF- $\alpha /$ IL- 6 monoclonal antibody was pre-coated on a high-affinity microplate using a double antibody sandwich enzyme-linked immunosorbent assay. Standard substance, the sample to be tested and the biotinylated detection antibody were added to the well of the plate, and after incubation, the TNF- $\alpha /$ IL- 6 present in the sample was combined with the solid phase antibody and the detection antibody. After washing to remove unbound material, horseradish peroxidase-labeled streptavidin-HRP was added. After washing, the chromogenic substrate TMB was added to avoid color development. Three sub holes were provided for each sample. The depth of the color reaction was directly proportional to the concentration of TNF- $\alpha / \mathrm{IL}-6$ in the sample. The reaction was terminated by the addition of a stop solution, and the absorbance value was measured at a wavelength of $450 \mathrm{~nm}$.

Flow cytometry detection of CD83/CD80: To assess the maturation level of DC 2.4 cells and RAW 264.7 cells after different treatments, including PBS, ICG@CaHPO, SEV@CaHPO and (SEV+ICG)@ $\mathrm{CaHPO}_{4}$ nanocomplexes were incubated for 48 hours. The cells were washed three times with PBS, then blocked with PBS containing $2 \%$ serum, and stained with anti-CD80-FITC and anti-CD83-FITC antibody (Abcam) for $30 \mathrm{~min}$ at $4{ }^{\circ} \mathrm{C}$. After washing with PBS, cell fluorescence was measured by FACS analysis (BD FACSCalibur). All samples were analyzed in triplicate. 
Detection of calcium ion: We used a fluorescence probe of intracellular calcium ion concentration of F03 (HR0943) to detect calcium ion concentration. Firstly, the F03 solution was diluted 1000 times with HBSS, and the F03 staining working solution was prepared. The cell sample of the $(\mathrm{SEV}+\mathrm{ICG}) @ \mathrm{CaHPO}_{4}$ nanocomposite was washed three times with HBSS. After the supernatant was aspirated, the F03 staining working solution was added to the cells. Incubation was then carried out for 30 minutes at $37^{\circ} \mathrm{C}$, followed by washing the cells 3 times with HBSS and then added the Hoechst (Solarbio, 33258) working solution, incubation was continued for another 30 minutes at $37^{\circ} \mathrm{C}$. It was then observed with an inverted fluorescence microscope (Olympus, IX73).

Apoptosis assay: To detect whether $\mathrm{Ca}^{2+}$ can induce apoptosis in $4 \mathrm{~T} 1$ tumor cells, we used the Annexin V-FITC/PI Apoptosis Detection Kit (Solarbio, CA1020) for detection. The Binding Buffer was diluted with deionized water, and the cells were collected by trypsinization and washed with PBS $\left(1 \times 10^{6}\right.$ cells/time $)$. The cells were suspended with $1 \times$ Binding Buffer, centrifuged at $300 \times \mathrm{g}$ for $10 \mathrm{~min}$, and the supernatant was discarded. The cells were then resuspended in $1 \times$ Binding Buffer to achieve a cell density of $1 \times 10^{6}$ cells $/ \mathrm{ml}$. $100 \mu \mathrm{L}$ of cells $\left(1 \times 10^{5}\right.$ cells) were added to each tube. $5 \mu \mathrm{L}$ of Annexin V-FITC and $5 \mu \mathrm{L}$ of PI were added to the tube, and the mixture was lightly mixed at room temperature for $10 \mathrm{~min}$. It was detected by flow cytometry (BD FACSCalibur) within $1 \mathrm{~h}$.

Photothermal killing of tumor cells in vitro: To detect the photothermal treatment effect of $(\mathrm{SEV}+\mathrm{ICG}) @ \mathrm{CaHPO}_{4}$ nanocomposites, the survival rate of 4T1 cells after different treatments was evaluated. After incubating them with $4 \mathrm{~T} 1$ cells for $4 \mathrm{~h}$, subjected to three treatments: no $808 \mathrm{~nm}$ laser irradiation, all of them were irradiated by 808 laser and part of them were irradiated by 808 laser $\left(1.0 \mathrm{~W} \mathrm{~cm}^{-2}\right)$. Then Calcein acetoxyl-methylester (Calcein AM) and propidium iodide (PI) were used for labeling living and death cells, respectively. Each hole was then washed with PBS and observed with an inverted fluorescence microscope (Nikon, Japan).

\section{In vivo synergistic immunotherapy against breast cancer with supervirus nanocomposites:}

Animal experiment: Bilateral breast cancer models were established by subcutaneously implanting 4T1 cells into the abdomen of BALB/c mice. When the tumor diameter reached 5-7 $\mathrm{mm}$, these mice were randomized into 6 groups ( $\mathrm{n}=5$ per group) for different treatments. PBS 
group: $50 \mathrm{ul}$ of sterile PBS was injected into the tumor of mice; NIR group: only the tumor site of the mice were irradiated by $808 \mathrm{~nm}$ laser with a density of $1.0 \mathrm{~W} \mathrm{~cm}^{-2}$ for $300 \mathrm{~s}$. ICG@ $\mathrm{CaHPO}_{4}$ group: 50 ul of ICG@ $\mathrm{CaHPO}_{4}$ nanocomposite was injected intratumorally into the tumor site of the mice and then irradiated with an 808 nm laser for $300 \mathrm{~s} . \mathrm{SEV} @ \mathrm{CaHPO}_{4}$ group: 50 ul SEV@ $\mathrm{CaHPO}_{4}$ nanocomposite was injected intratumorally into the tumor site of mice with laser irradiation. (SEV+ICG)@ $\mathrm{CaHPO}_{4}$ group: 50 ul (SEV+ICG)@ $\mathrm{CaHPO}_{4}$ nanocomposite was injected intratumorally in the tumor site of the mouse without laser irradiation. (SEV+ICG)@CaHPO ${ }_{4}+\mathrm{NIR}$ group: 50 ul (SEV+ICG)@ $\mathrm{CaHPO}_{4}$ nanocomposite was injected intratumorally into the tumor site of the mouse, and then irradiated with $808 \mathrm{~nm}$ laser for $300 \mathrm{~s}\left(1.0 \mathrm{~W} \mathrm{~cm}^{-2}\right)$. All the animal experiments involved in this work were approved by the Animal Ethics Committee of Institute of Radiology Medicine, Chinese academy of medical sciences.

T cell scavenging animal experiments: Bilateral breast cancer models were established by subcutaneously implanting $4 \mathrm{~T} 1$ cells into the abdomen of BALB/c mice. These mice were randomized into three groups ( $\mathrm{n}=5$ per group) for different immune clearance by intraperitoneal injection. PBS group: sterile PBS was injected into the tumor of mice; Anti-CD3 antibody: $50 \mu \mathrm{g}$ anti-CD3 antibody was injected into the tumor of mice; IgG: $50 \mu \mathrm{g} \operatorname{IgG}$ was injected into the tumor of mice. After intraperitoneal injection of anti-CD3 antibody twice a week, $50 \mu \mathrm{g}$ $(\mathrm{SEV}+\mathrm{ICG}) @ \mathrm{CaHPO}_{4}$ nanocomposite was injected intratumorally into the tumor site of the mouse, and then irradiated with $808 \mathrm{~nm}$ laser for $300 \mathrm{~s}$. Subsequently, the lymphocytes were monitored by flow cytometry and tumor size was measured daily for statistics.

Nude mice experiment: A bilateral breast cancer model was established by subcutaneously implanting 4T1 cells into the abdomen of nude mice. When the tumor diameter reached 5-7 mm, these mice were randomized into three groups ( $\mathrm{n}=5$ per group) for different treatments in one side. PBS group: sterile PBS was injected into the tumor of mice; (SEV+ICG)@ $\mathrm{CaHPO}_{4}$ group: $50 \mu \mathrm{g}$ (SEV+ICG)@CaHPO ${ }_{4}$ nanocomposite was injected intratumorally in the tumor site of the mouse without laser irradiation. (SEV+ICG)@ $\mathrm{CaHPO}_{4}+\mathrm{NIR} \quad$ group: $\quad 50 \quad \mu \mathrm{g}$ (SEV+ICG)@CaHPO ${ }_{4}$ nanocomposite was injected intratumorally into the tumor site of the mouse, and then irradiated with $808 \mathrm{~nm}$ laser for $300 \mathrm{~s}$. Subsequently, the tumor size was measured daily for statistics. 
Fluorescence and photothermal performance monitoring in vivo: After various treatments, in vivo imaging of $4 \mathrm{~T} 1$ tumor-bearing mice was performed using in vivo living imaging system (IVIS SPECTRUM) to obtain in vivo fluorescence images of tumors and major organs. IR heat images of tumor sites with differently administered mice were recorded by IR camera during irradiation with $808 \mathrm{~nm}$ laser. The size of the tumor and the change in body weight of the mice were then monitored daily.

Activation of APCs monitoring: To investigate the cytotoxic $T$ cell response of intratumoral injection of nanocomplexes to 4T1-bearing mice, tumor blocks and tumor infiltrating fluid from each group of mice were gathered for immunohistochemical staining of CD3 and CD8 on day 5 after various treatments. Tumor sections were H\&E stained and TUNEL stained to observe the tumor necrosis and apoptosis.

Cytokine measurement: The level of expression of cytokines in tumor infiltrating fluid collected from mice in therapeutic experiments was measured using an enzyme linked immunosorbent assay (ELISA) kit against IFN- $\gamma /$ TNF- $\alpha /$ IL-6. All samples were analyzed in triplicate.

CTLs Level Measurement: In order to evaluate the T cell level of tumor cells after different treatments, on the 5 th day after various treatments, tumor tissues were excised, $\mathrm{T}$ cells were isolated, washed with PBS, stained by with anti-CD3-FITC and anti-CD8-PE antibody (Abcam) for 30 min at $4{ }^{\circ} \mathrm{C}$, and subjected to FACS analysis (BD FACSCalibur) for $\mathrm{CD}^{+}$Fluorescence detection of $\mathrm{CD} 8^{+} \mathrm{T}$ cells.

\section{Statistical Analyses}

Data were expressed as mean \pm standard deviation (SD) of experiments and each experiment group contained 5 repeated samples. Data analysis was performed using OriginPro 9.0 and Microsoft Excel. The significance between groups were analyzed using unpaired two-tailed t-test (compared two groups) and one-way analysis of variance (ANOVA) (compared multiple groups) by Statistics Analysis System ( ${ }^{*} \mathrm{p}<0.05$ and ${ }^{* *} \mathrm{p}<0.01$, respectively). $\mathrm{p}<0.05$ was considered as significant. 


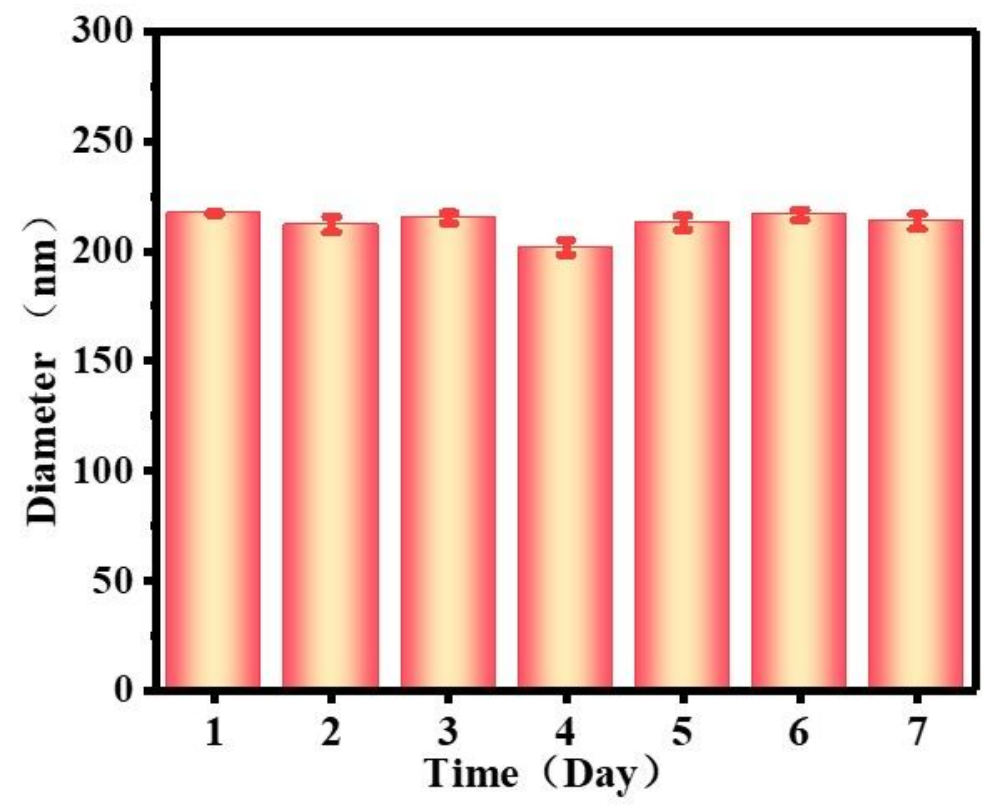

Figure S1. The stability of virus-inorganic nanohybrids in normal saline at different time. 


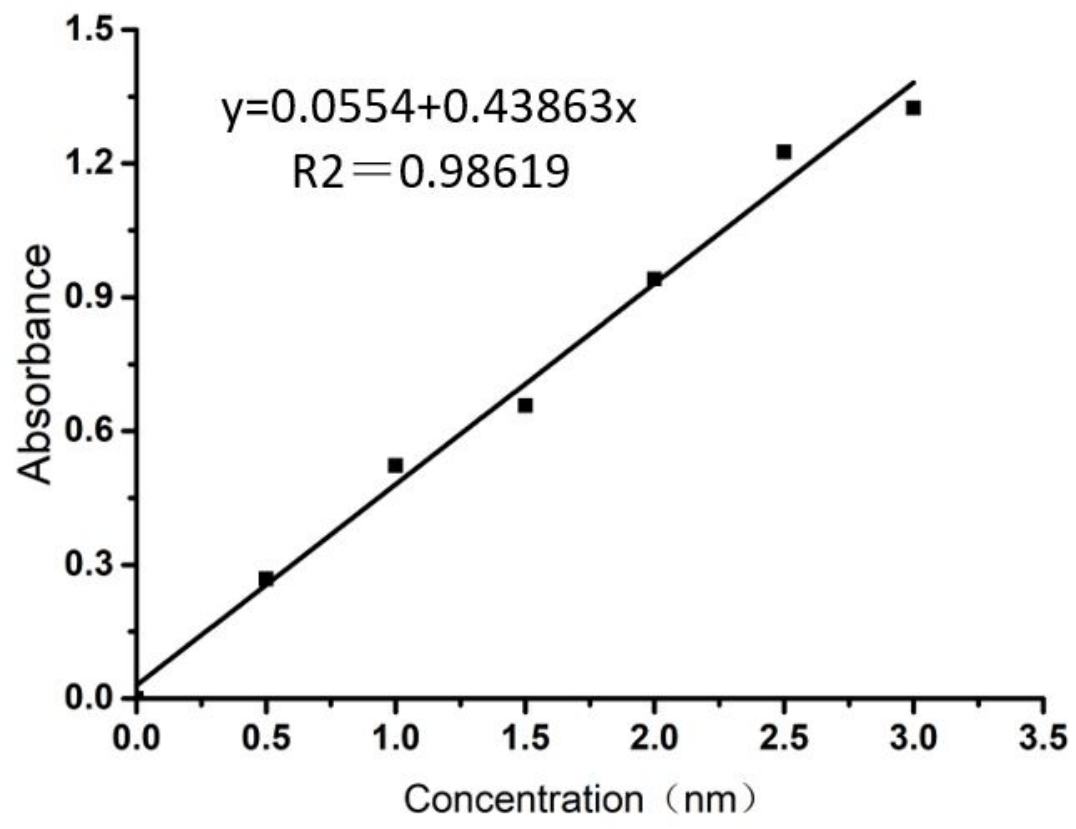

Figure S2. The standard cure of ICG about the relationship between absorption value and the concentration. Encapsulation Efficiency $=(1-(1.56 / 2.5)) * 100 \%=37.6 \%$. 


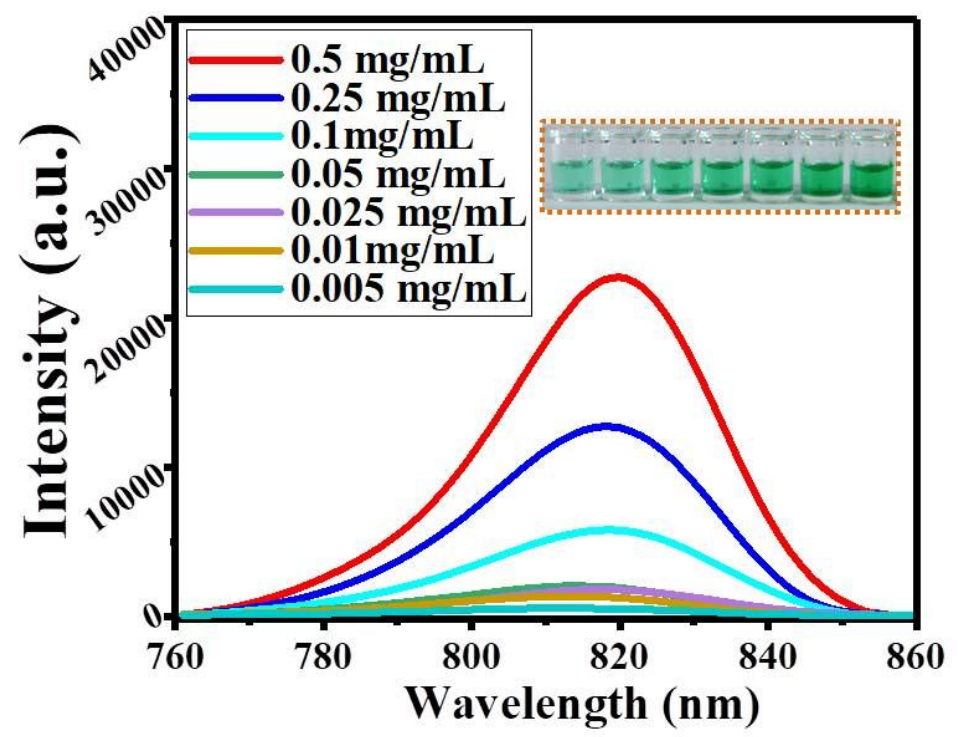

Figure S3. The Fluorescence performance detection of different (SEV+ICG)@CaHPO 4 nanocomposites concentrations. The illustration is a macro photo. 

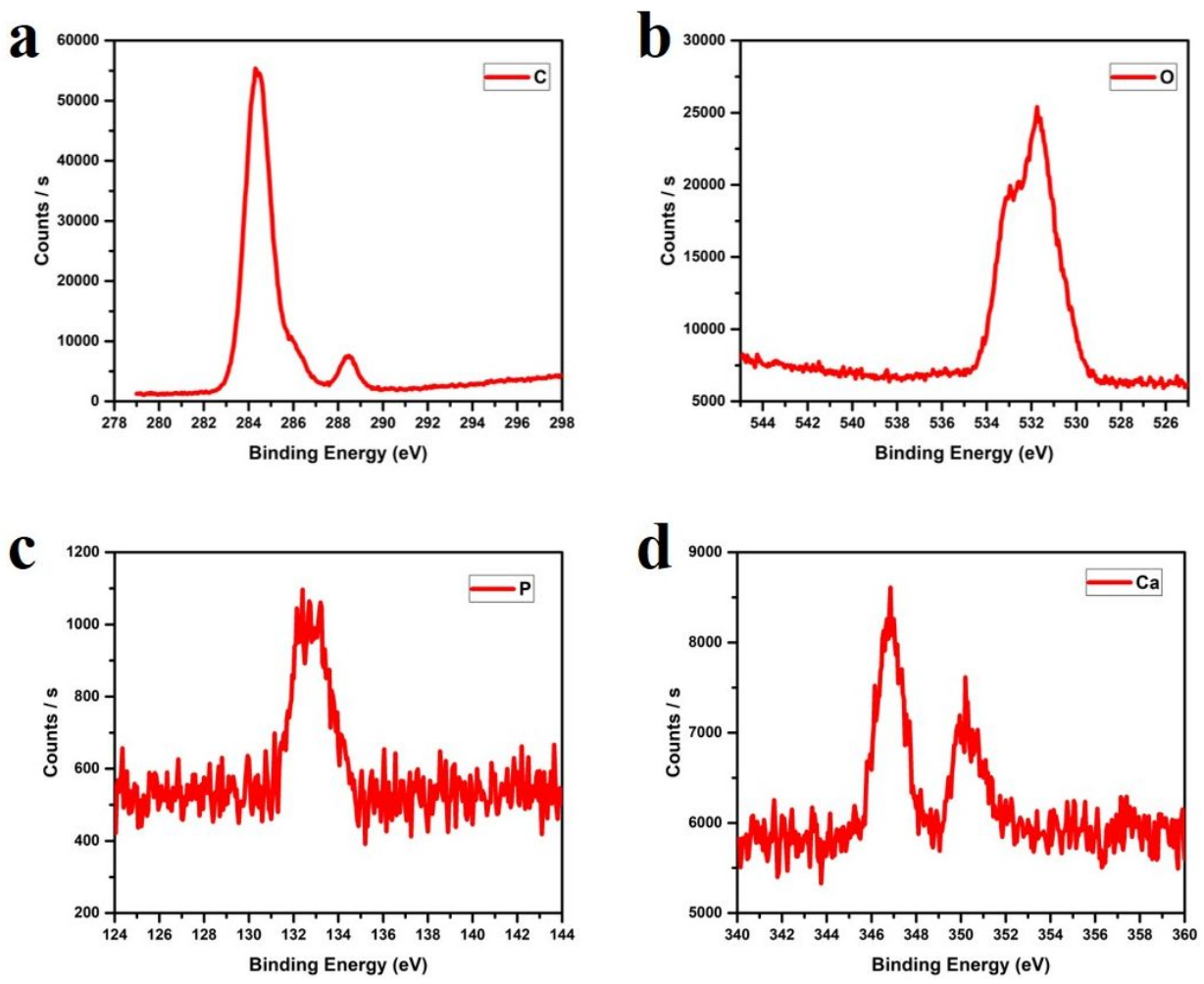

Figure S4. X-ray photoelectron spectroscopy (XPS) of (a) C, (b) O, (c) P, (d) Ca elements in virus-inorganic nanohybrids. 


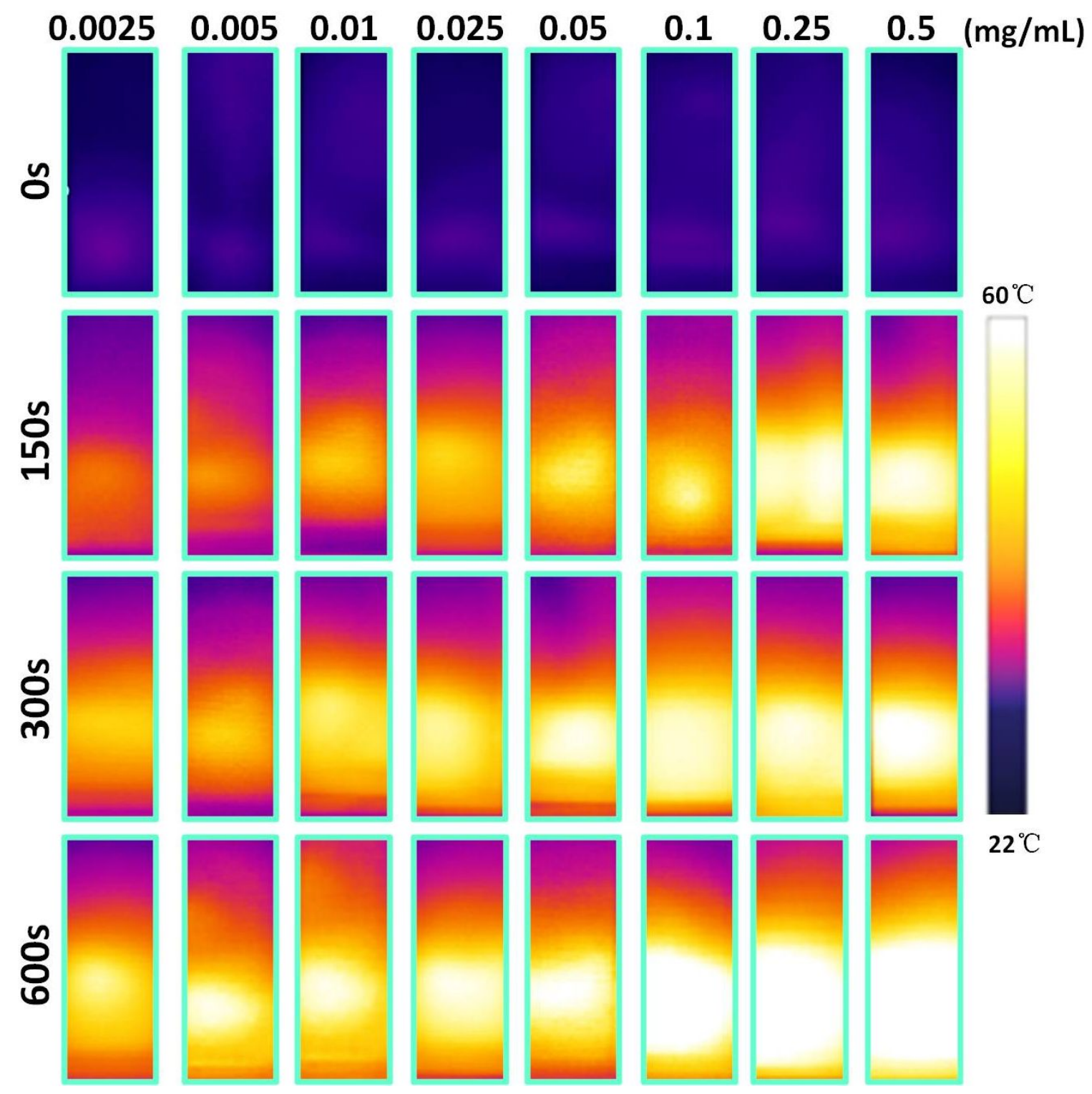

Figure S5. The IR thermal images of different (SEV+ICG)@CaHPO $\mathrm{CaH}_{4}$ nanocomposites concentrations under $808 \mathrm{~nm}$ near-infrared light $\left(1.0 \mathrm{~W} \mathrm{~cm} \mathrm{~cm}^{-2}\right)$. 


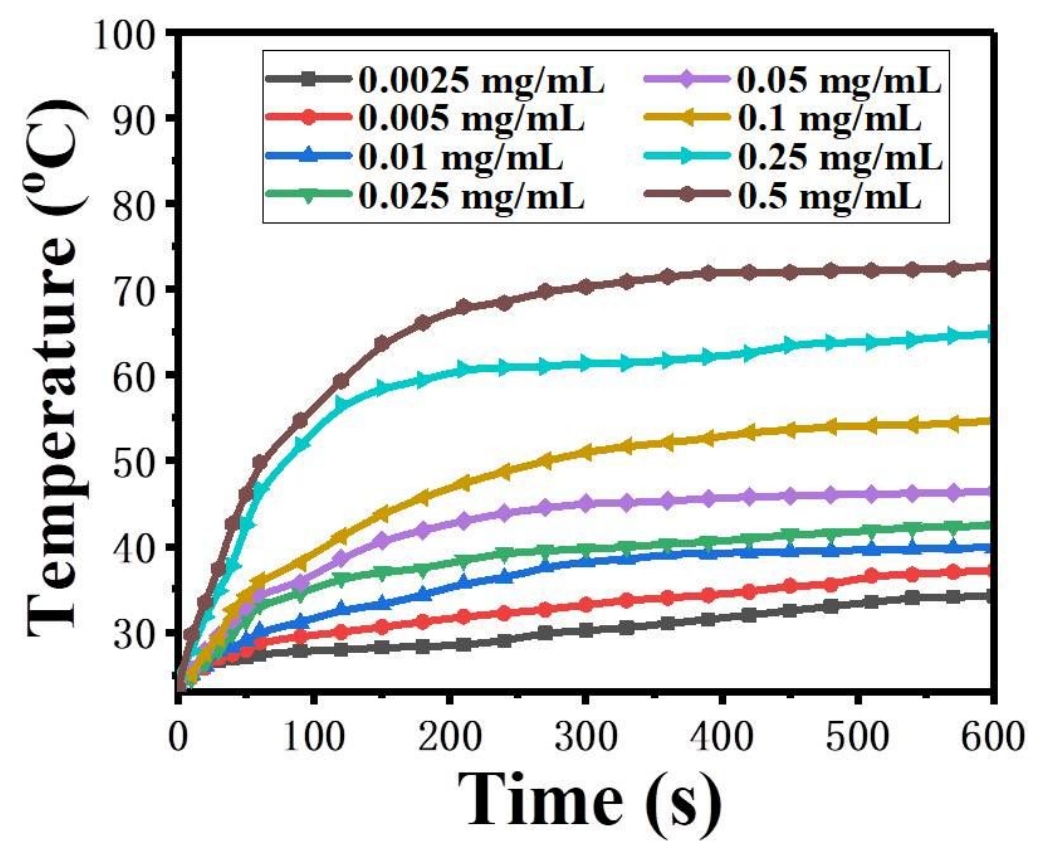

Figure S6. The photothermal conversion performance of different (SEV+ICG)@CaHPO nanocomposites concentrations under $808 \mathrm{~nm}$ near-infrared light $\left(1.0 \mathrm{~W} \mathrm{~cm} \mathrm{~cm}^{-2}\right)$. 

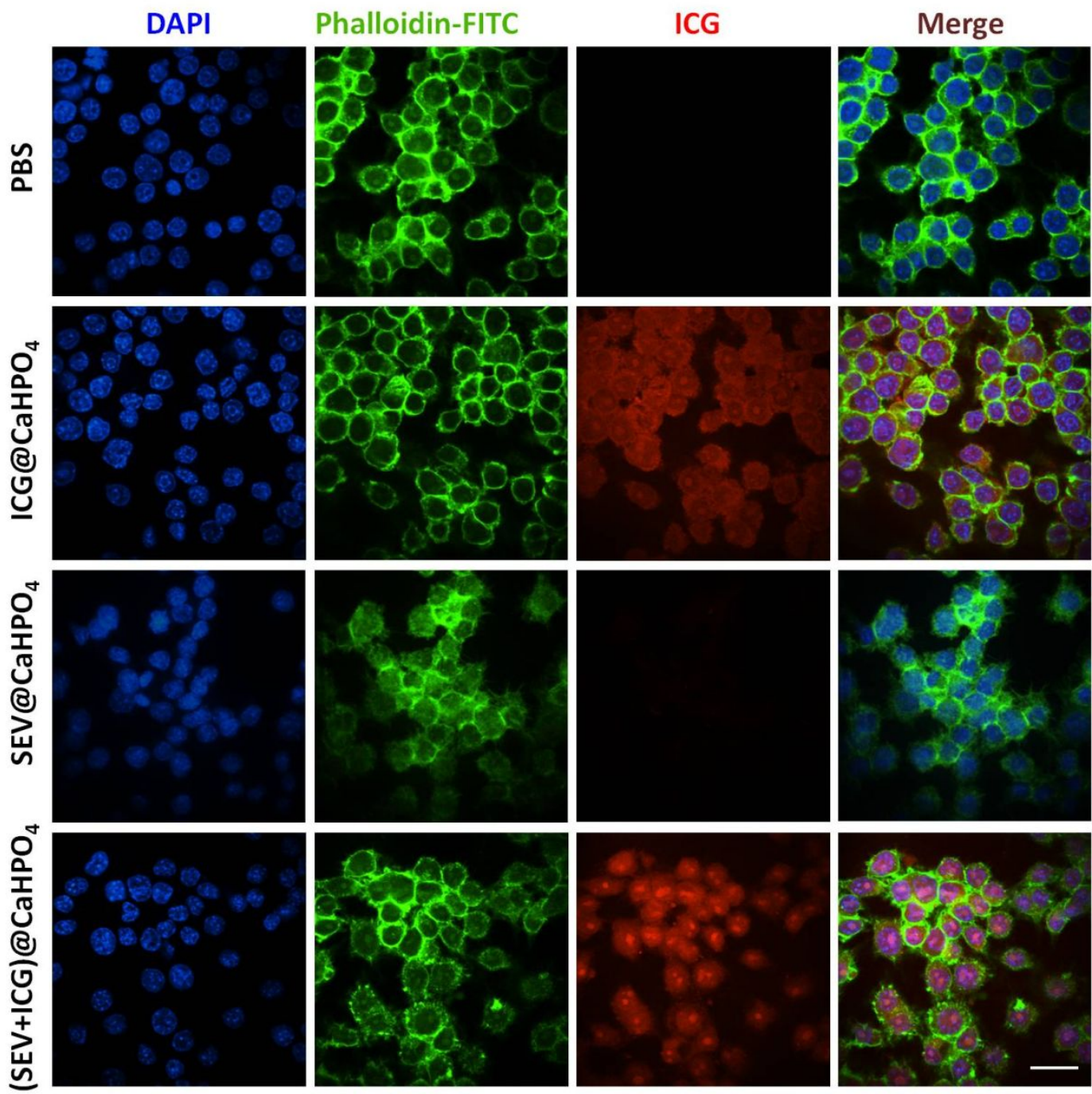

Figure S7. Endocytosis in DC 2.4 cells of different samples and the results were visualized by laser scanning confocal microscope. The scale bars were $50 \mu \mathrm{m}$. 

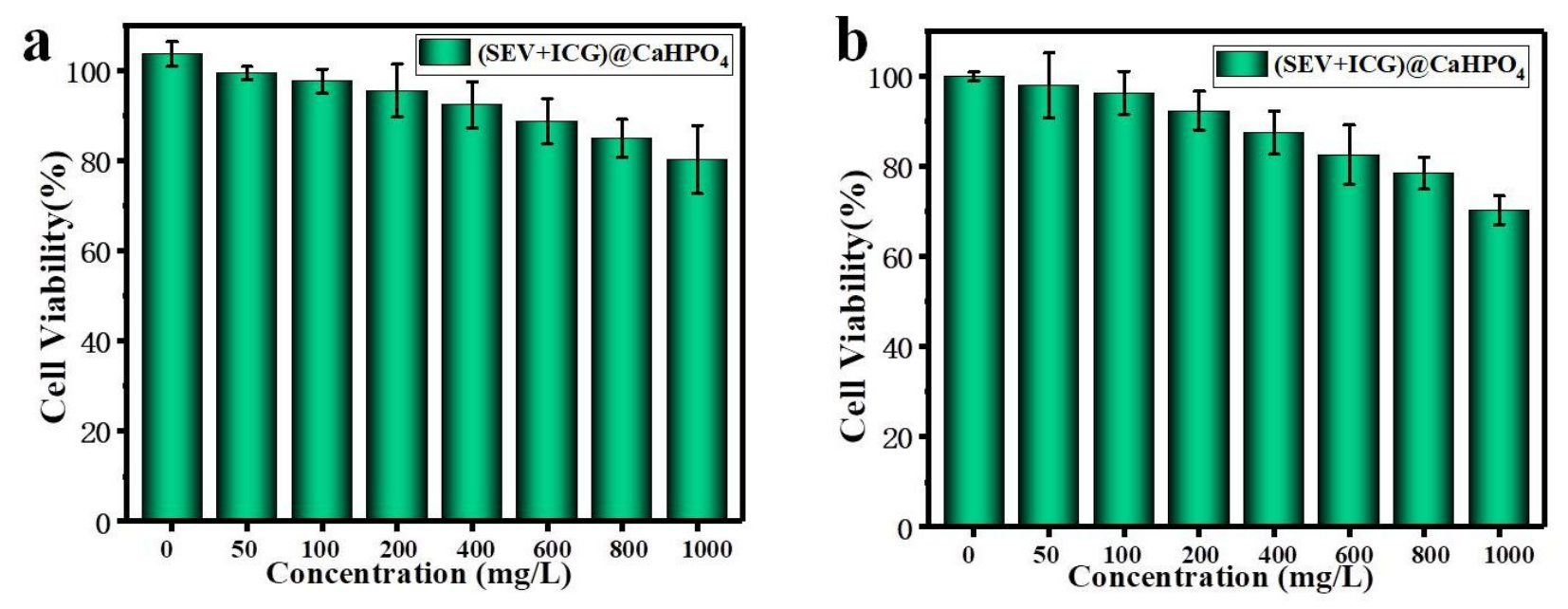

Figure S8. Cytotoxicity data of (SEV+ICG)@ $\mathrm{CaHPO}_{4}$ nanocomposites tested by MTT in a) DC 2.4 cells and b) RAW 264.7 cells. 


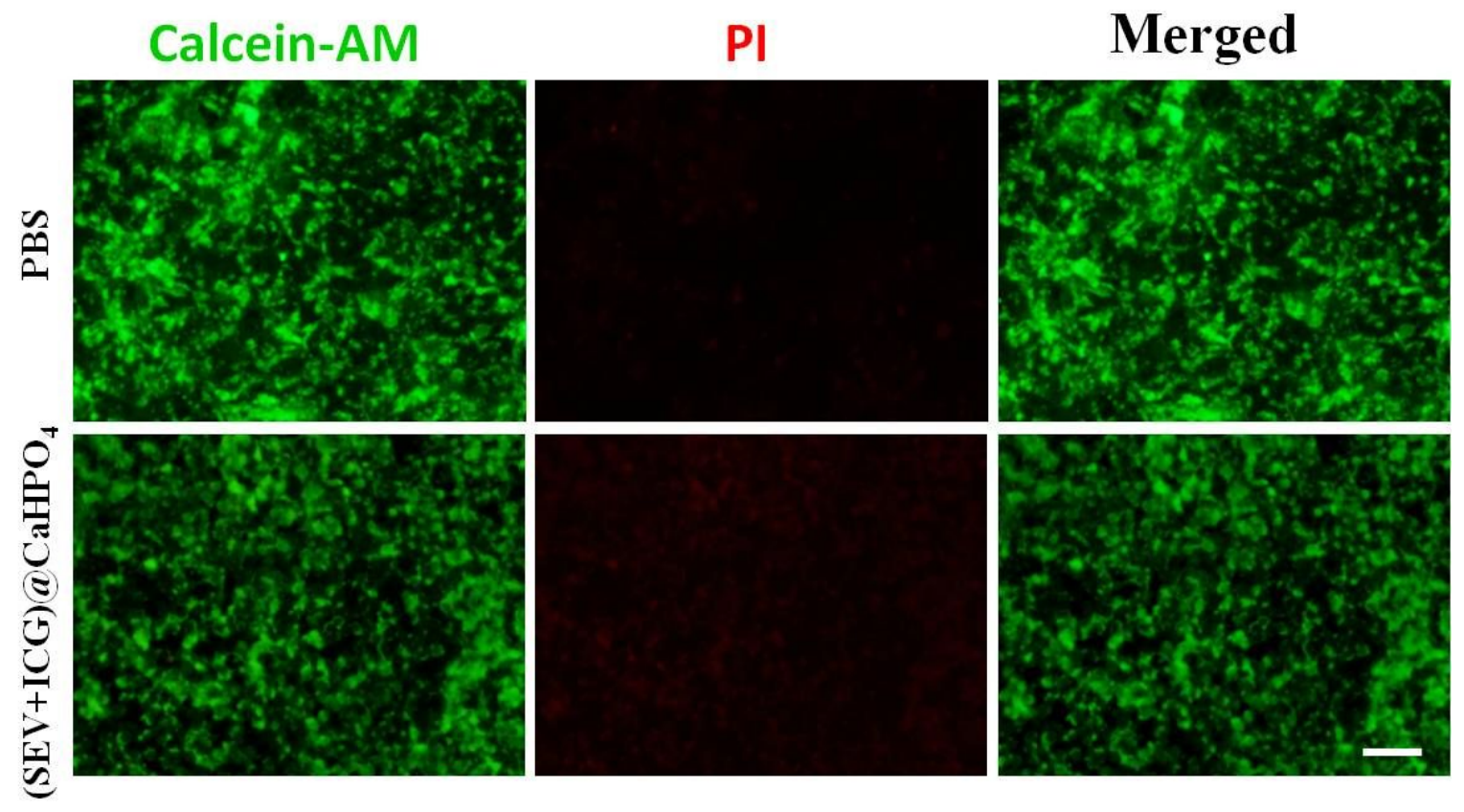

Figure S9. The biocompatibility of the (SEV+ICG)@CaHPO 4 nanocomposites in DC 2.4 cells. The green fluorescent dye, calcein-AM, was used to label the live cells for DC 2.4 cells and the results were visualized by fluorescence microscope. The scale bars were $200 \mu \mathrm{m}$. 

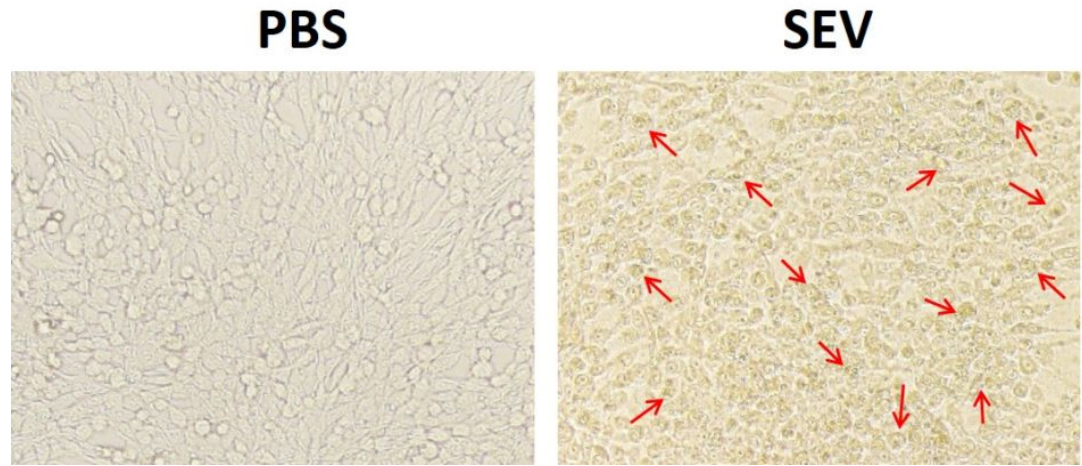

(SEV+ICG)@CaHPO

Figure S10. The Performance test of Sendai virus infecting C6 cells after biomineralization. The scale bars were $100 \mu \mathrm{m}$. 
$\mathbf{0} \mathbf{m g} / \mathbf{m L}$

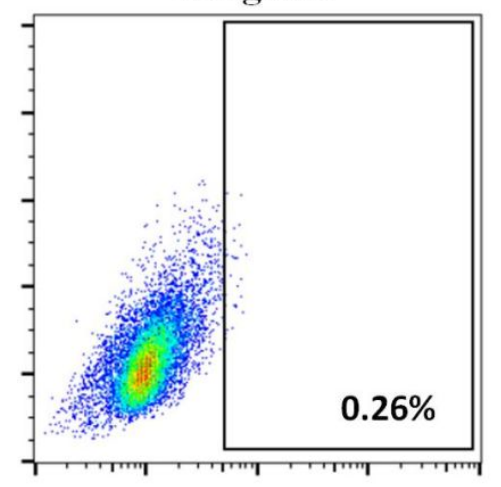

$0.6 \mathrm{mg} / \mathrm{mL}$

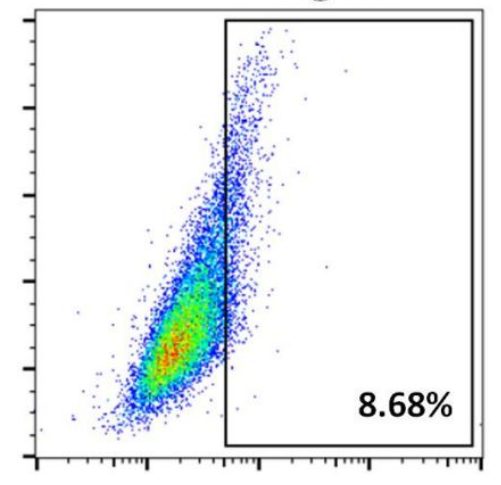

$0.2 \mathrm{mg} / \mathrm{mL}$

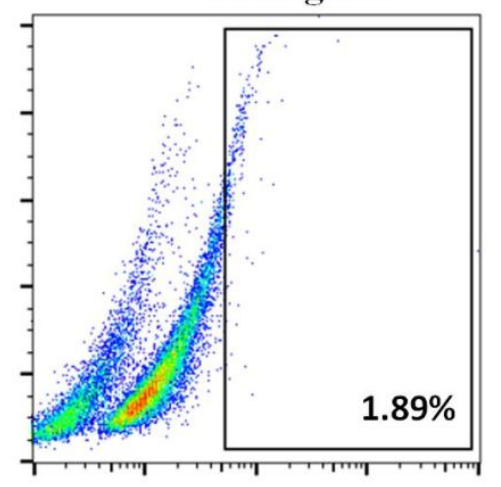

$0.8 \mathrm{mg} / \mathrm{mL}$

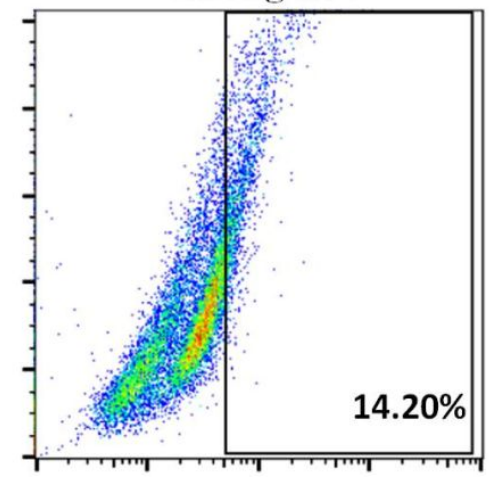

$0.4 \mathrm{mg} / \mathrm{mL}$

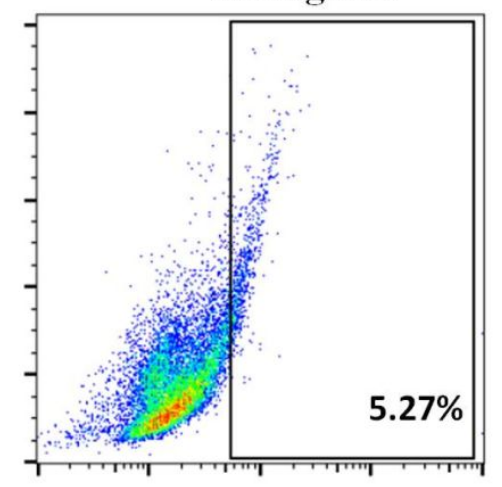

$1 \mathrm{mg} / \mathrm{mL}$

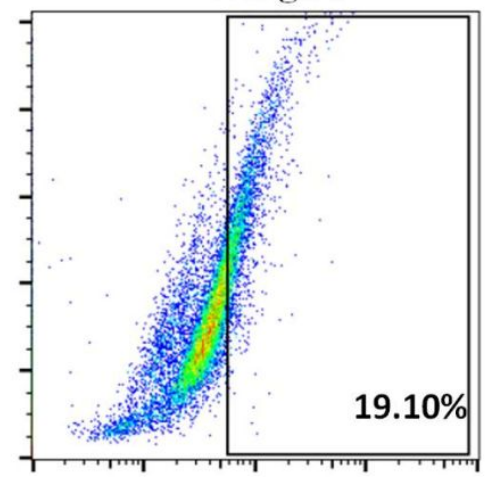

Figure S11. The CD80 molecules on the DC 2.4 cell surface were detected by flow cytometry (FCM) after 48 h of different concentrations of $(\mathrm{SEV}+\mathrm{ICG}) @ \mathrm{CaHPO}_{4}$ nanocomposites treatment. 
$0 \mathrm{mg} / \mathrm{mL}$

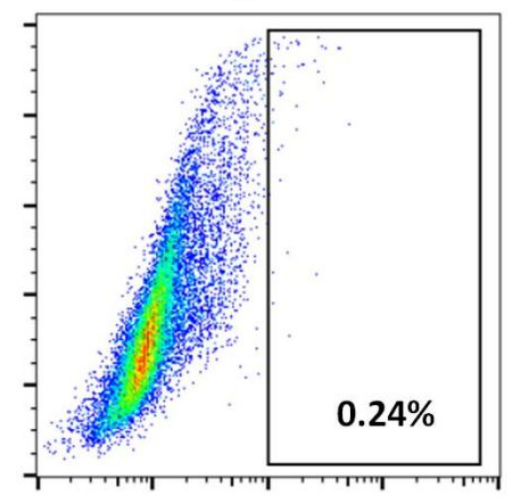

$0.6 \mathrm{mg} / \mathrm{mL}$

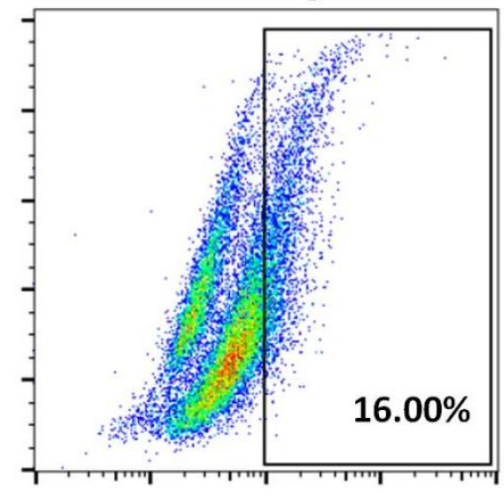

$0.2 \mathrm{mg} / \mathrm{mL}$

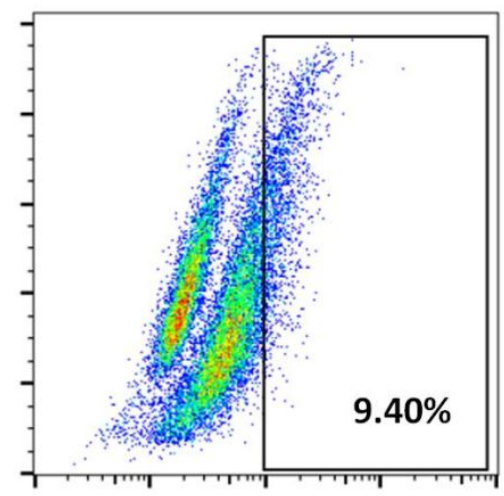

$0.8 \mathrm{mg} / \mathrm{mL}$

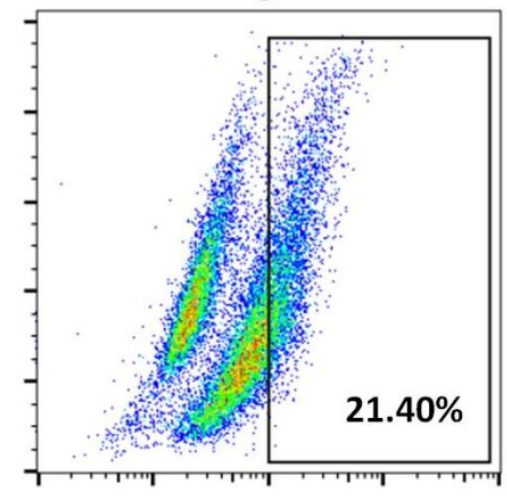

$0.4 \mathrm{mg} / \mathrm{mL}$

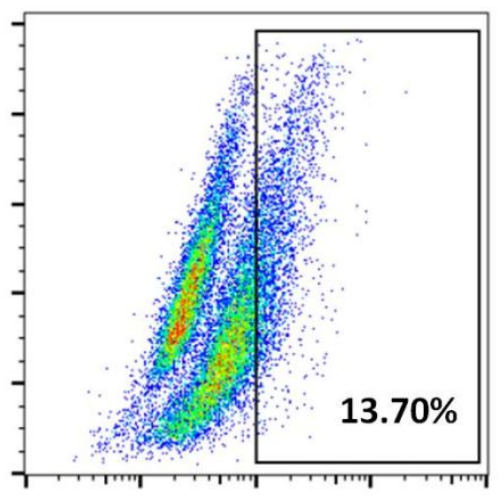

$1 \mathrm{mg} / \mathrm{mL}$

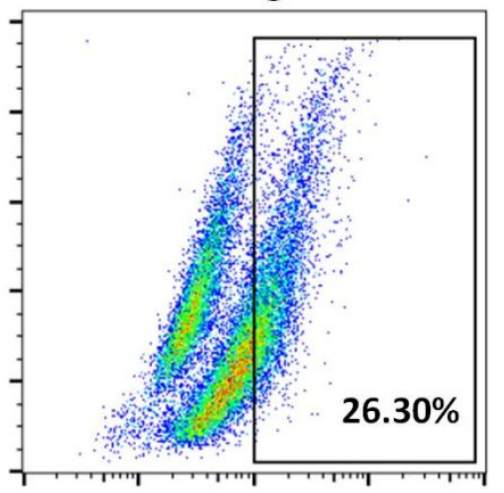

Figure S12. The CD83 molecules on the DC 2.4 cell surface were detected by flow cytometry (FCM) after 48 h of different concentrations of $(\mathrm{SEV}+\mathrm{ICG}) @ \mathrm{CaHPO}_{4}$ nanocomposites treatment. 
$0 \mathrm{mg} / \mathrm{mL}$

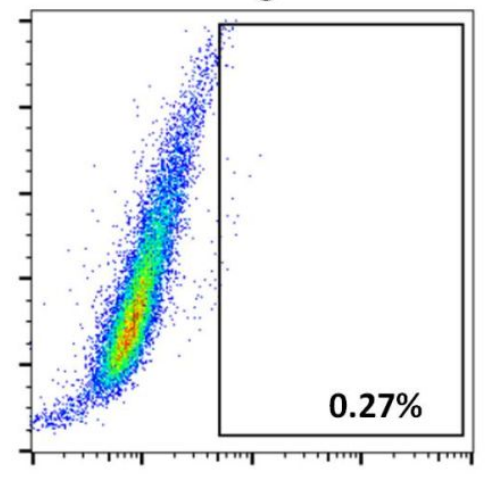

$0.6 \mathrm{mg} / \mathrm{mL}$

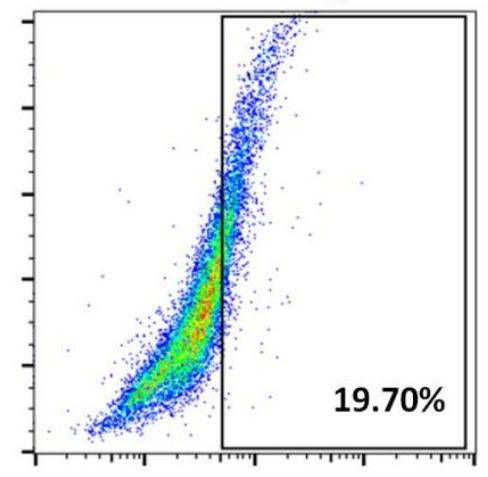

$0.2 \mathrm{mg} / \mathrm{mL}$

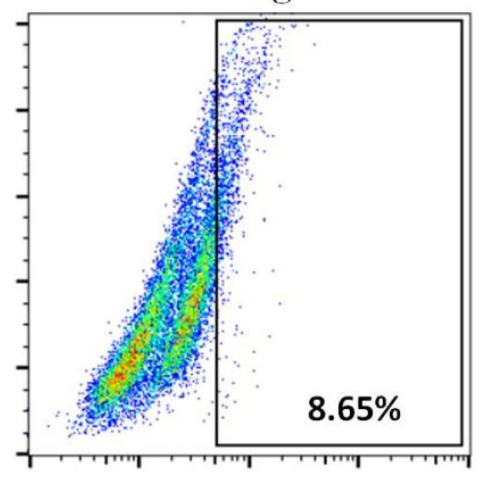

$0.8 \mathrm{mg} / \mathrm{mL}$

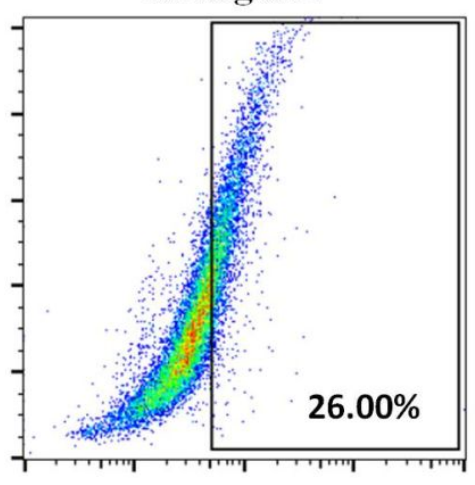

$0.4 \mathrm{mg} / \mathrm{mL}$

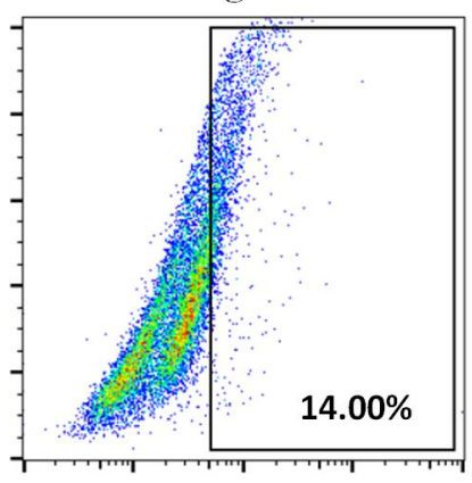

$1 \mathrm{mg} / \mathrm{mL}$

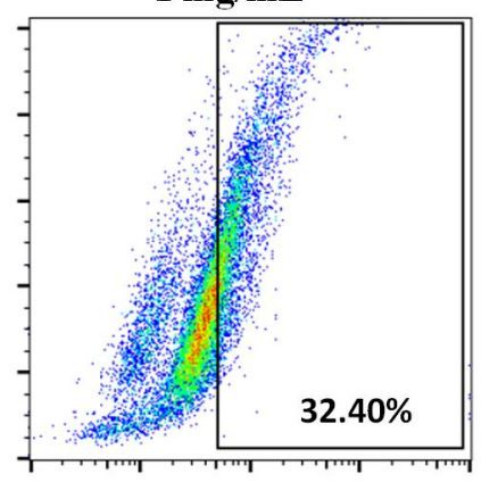

Figure S13. The CD80 molecules on the RAW 264.7 cell surface were detected by flow cytometry (FCM) after $48 \mathrm{~h} \quad$ of different concentrations of (SEV+ICG)@CaHPO nanocomposites treatment. 

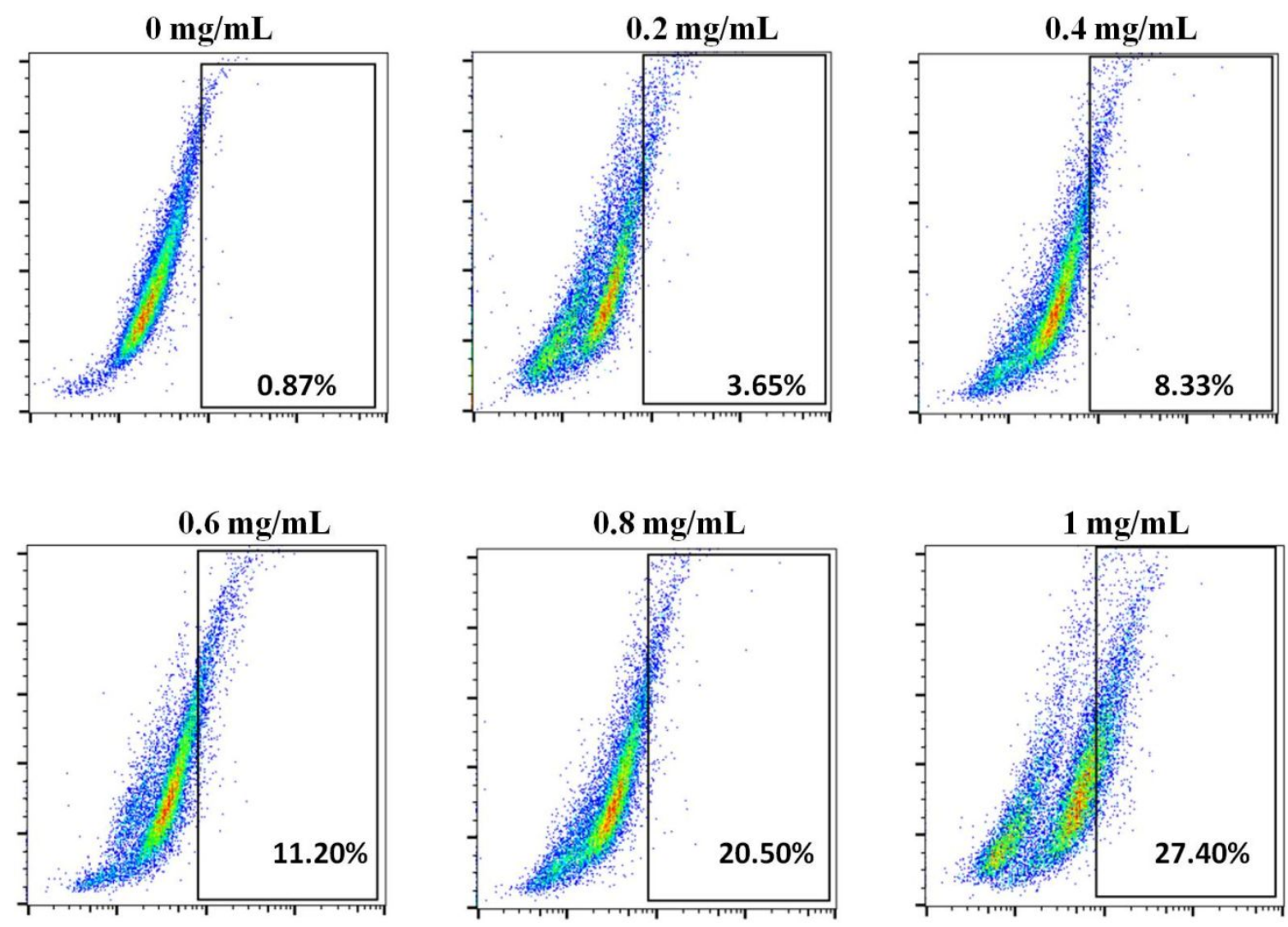

Figure S14. The CD83 molecules on the RAW 264.7 cell surface were detected by flow cytometry (FCM) after $48 \mathrm{~h}$ of different concentrations of (SEV+ICG)@CaHPO nanocomposites treatment. 


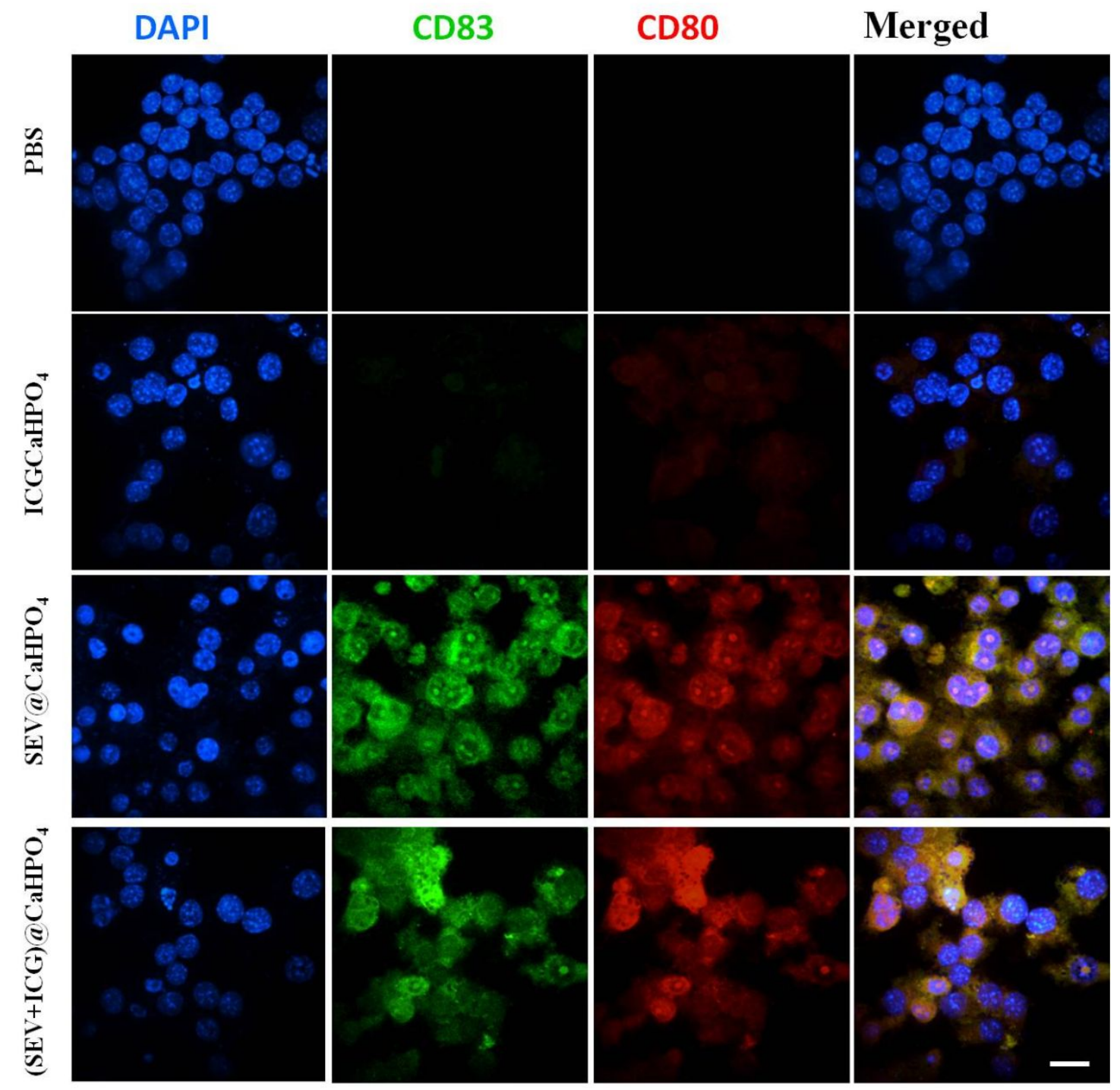

Figure S15. The CD80 and CD83 molecules on the RAW 264.7 cells were detected by immunofluorescence staining after 48 h of $(\mathrm{SEV}+\mathrm{ICG}) @ \mathrm{CaHPO}_{4}$ nanocomposites treatment. The scale bars were $50 \mu \mathrm{m}$. 


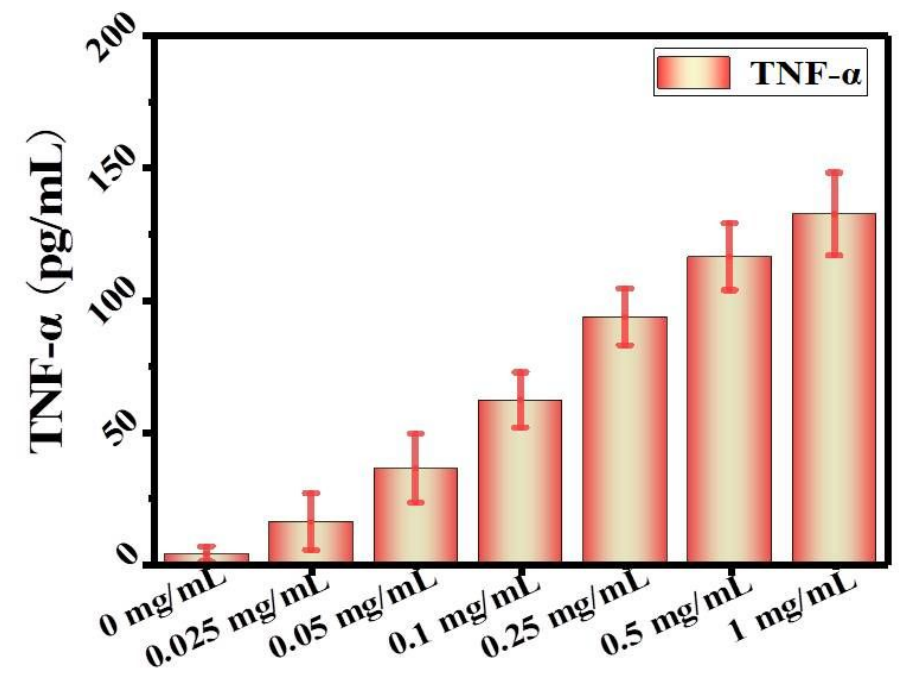

Figure S16. A preliminary quantitative analysis of the produced TNF- $\alpha$ was performed in the DC 2.4 cells culture supernatant after incubation with different (SEV+ICG)@CaHPO nanocomposites concentrations for $48 \mathrm{~h}$. Data are presented as mean $\pm \operatorname{SEM}(n=5)$. 


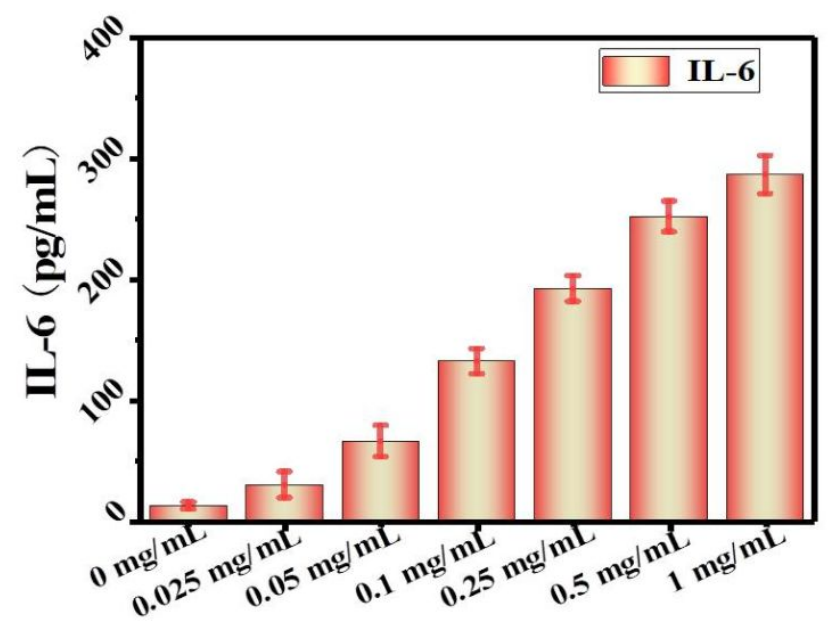

Figure S17. A preliminary quantitative analysis of the produced IL-6 was performed in the DC 2.4 cells culture supernatant treatmented with different $(\mathrm{SEV}+\mathrm{ICG}) @ \mathrm{CaHPO}_{4}$ nanocomposites concentrations for $48 \mathrm{~h}$. Data are presented as mean $\pm \operatorname{SEM}(n=5)$. 


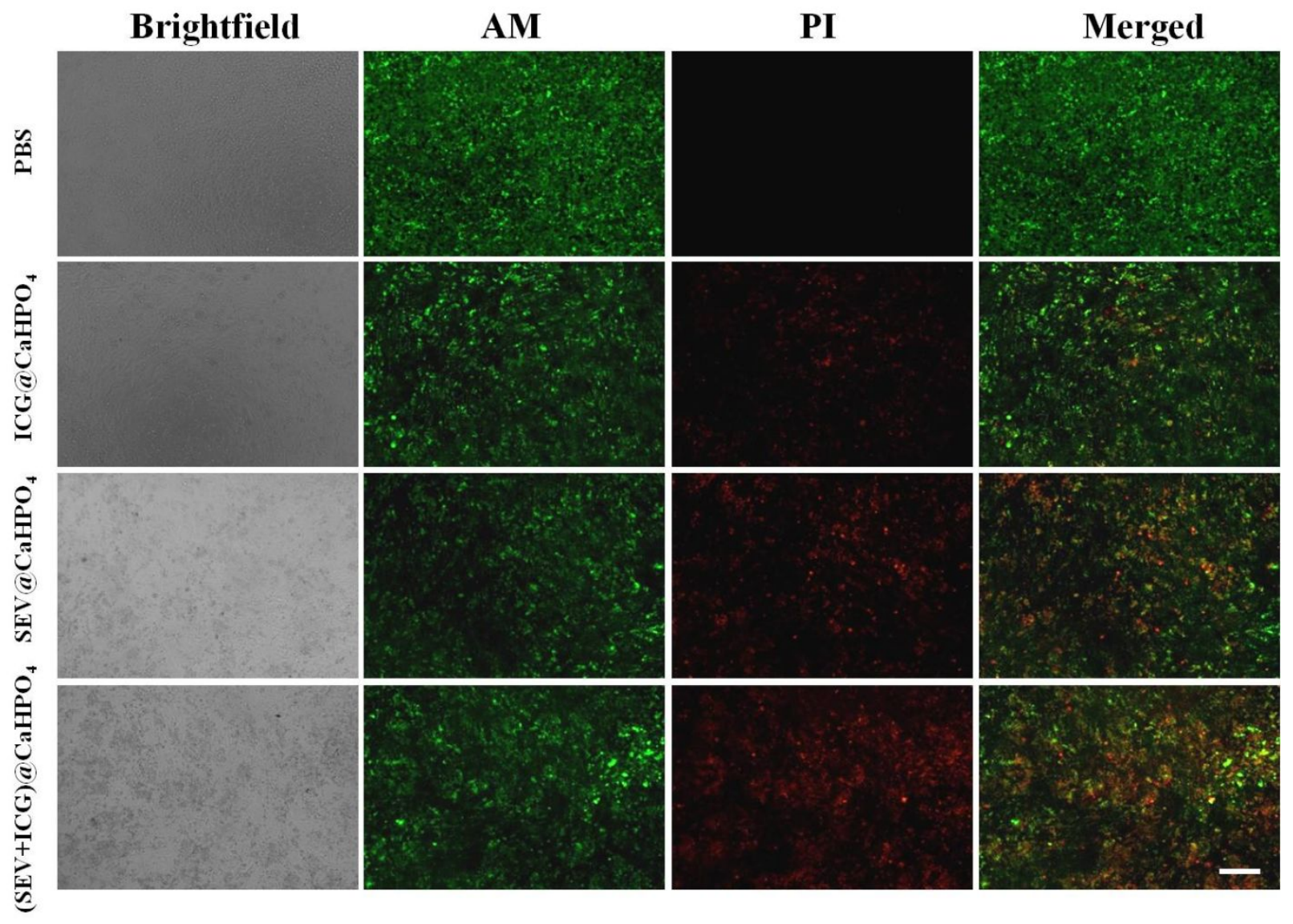

Figure S18. Apoptosis of 4T1 cells was detected by fluorescence microscope after incubation with different treatments for $48 \mathrm{~h}$. The scale bars were $200 \mu \mathrm{m}$. 


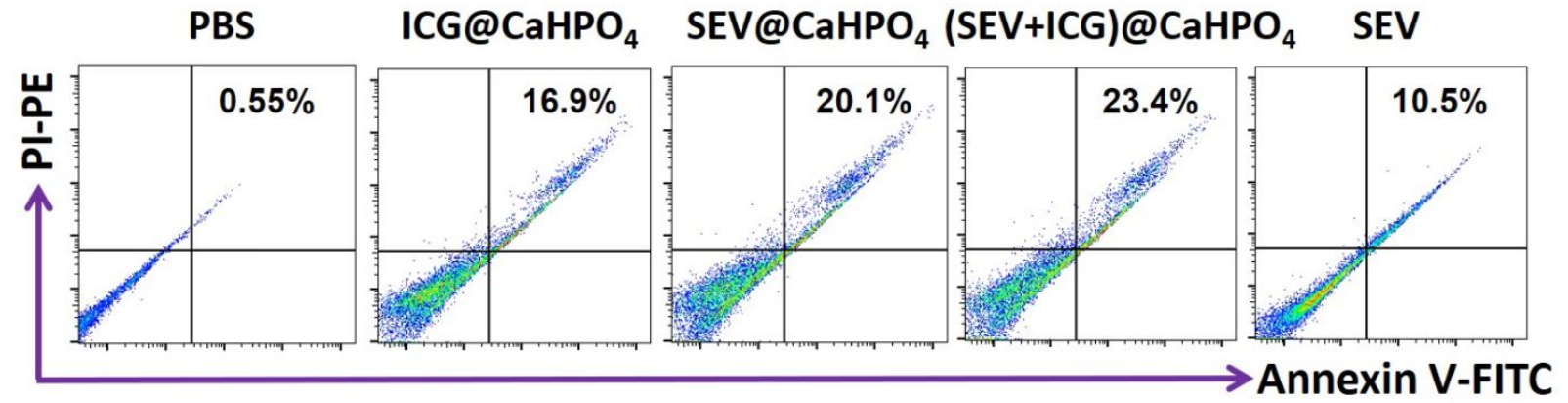

Figure S19. Flow cytometry analysis of apoptosis of $4 \mathrm{~T} 1$ cells induced by Sendai virus before and after biomineralization. 


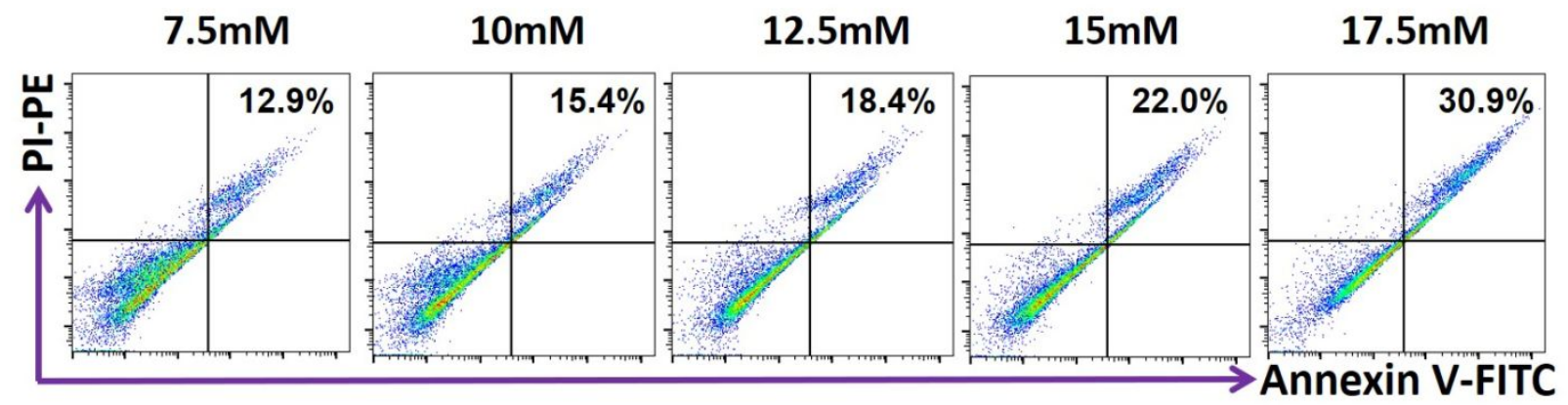

Figure S20. After the virus-inorganic nanohybrids were ablated by hydrochloric acid, the released calcium ions induced apoptosis of $4 \mathrm{~T} 1$ cells by flow cytometry analysis. 


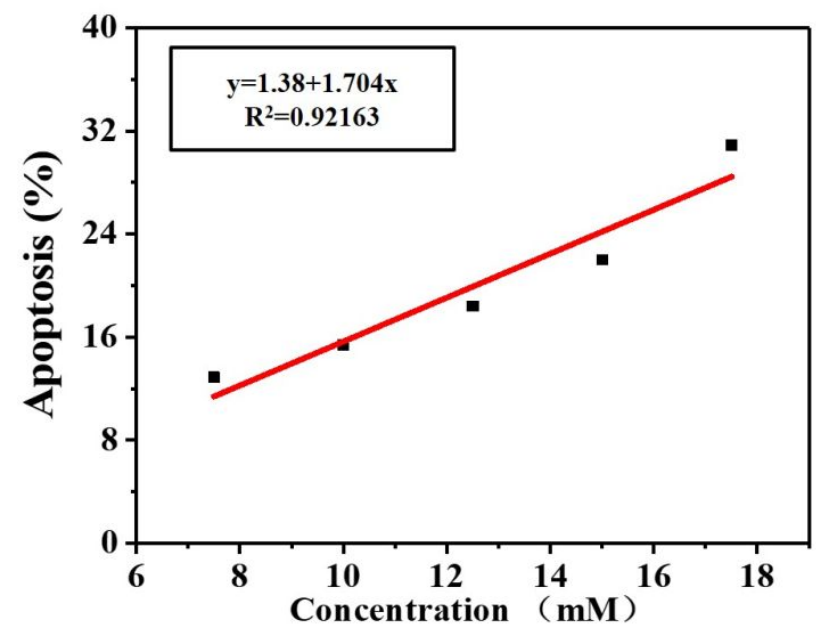

Figure S21. The correlation between calcium ion released from nanohybrids after ablation and apoptosis of 4T1 cells was analyzed. 


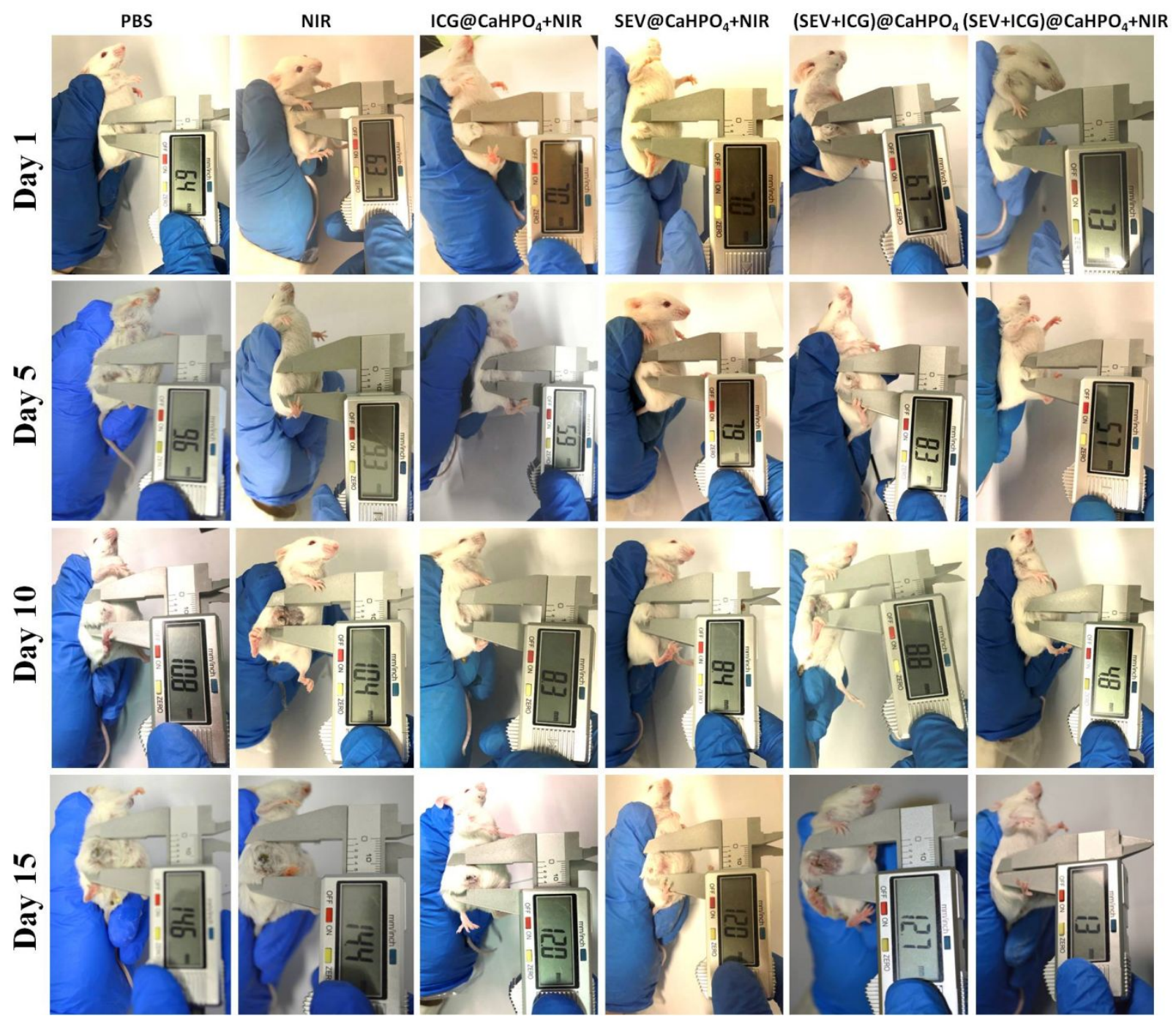

Figure S22. Macroscopic photographs of tumor changes in 4T1-bearing mice after different sample treatments. 
a
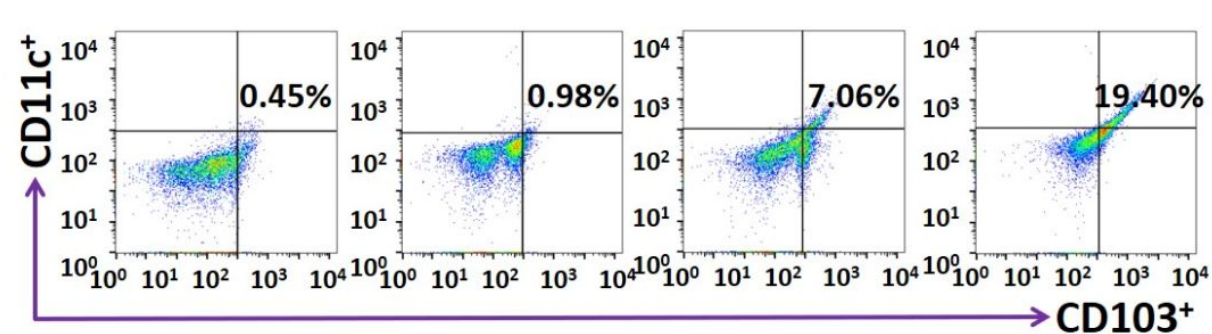

b
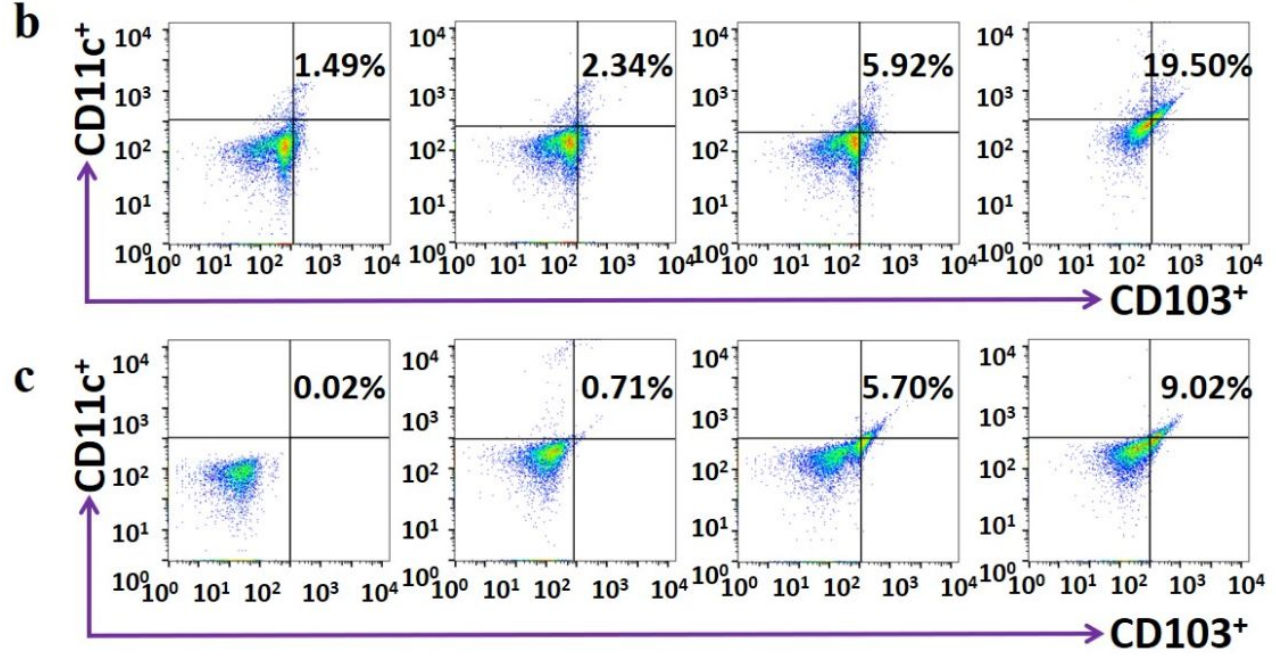
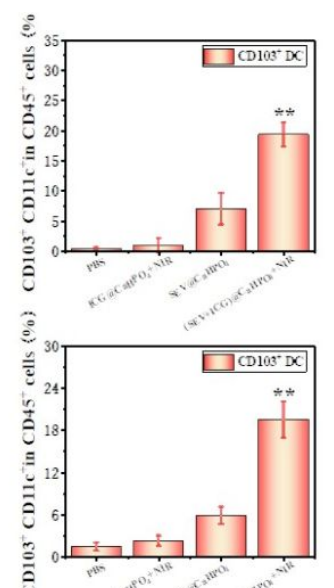

政

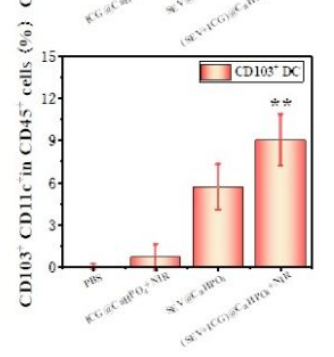

Figure S23. Flow cytometry for quantitative detection of $\mathrm{CD}_{103}{ }^{+}$dendritic cells throughout the body. a) lymph gland, b) spleen and c) blood. 

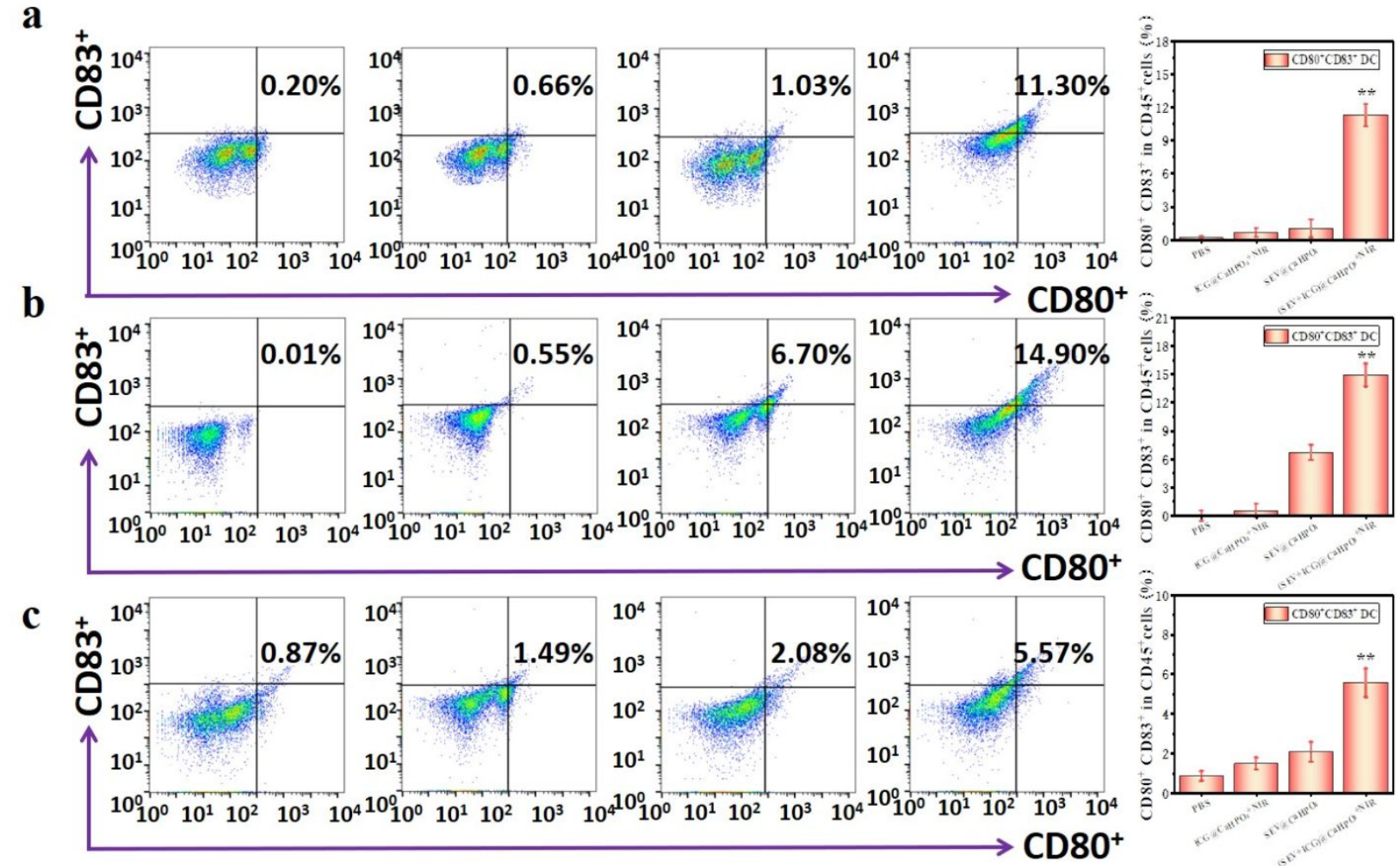

Figure S24. Flow cytometry for quantitative detection of $\mathrm{CD} 80^{+} \mathrm{CD} 83^{+}$dendritic cells throughout the body. a) lymph gland, b) spleen and c) blood. 

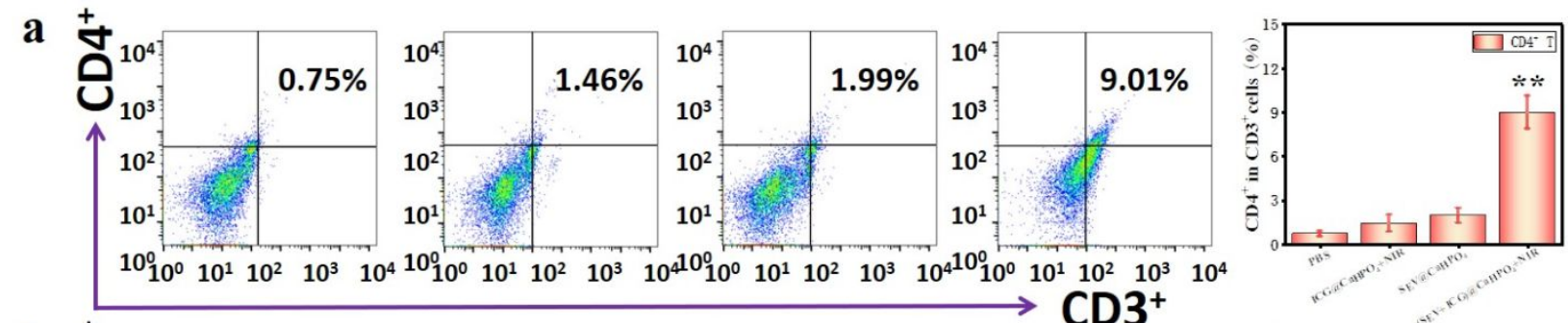

b
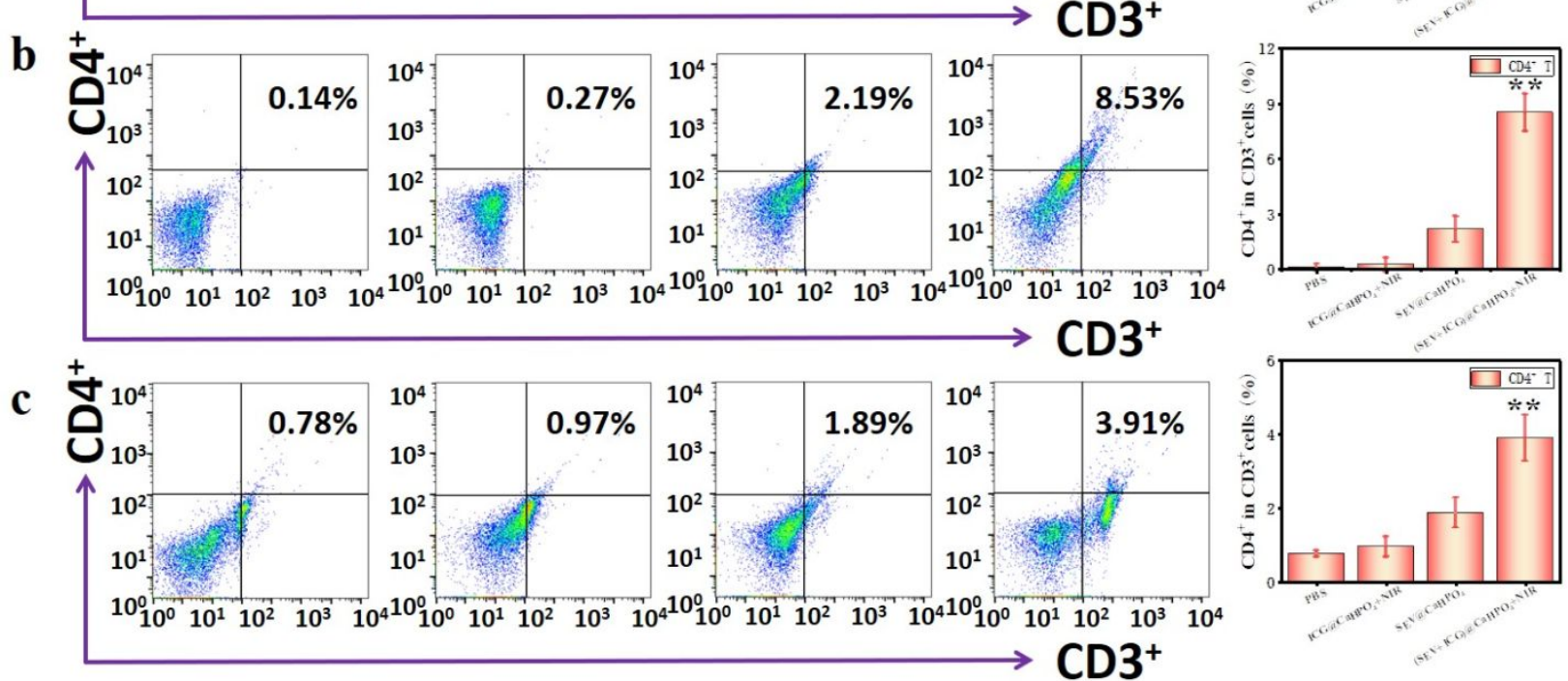

Figure S25. Flow cytometry for quantitative detection of $\mathrm{CD}^{+} \mathrm{T}$ cells throughout the body. a) lymph gland, b) spleen and c) blood. 


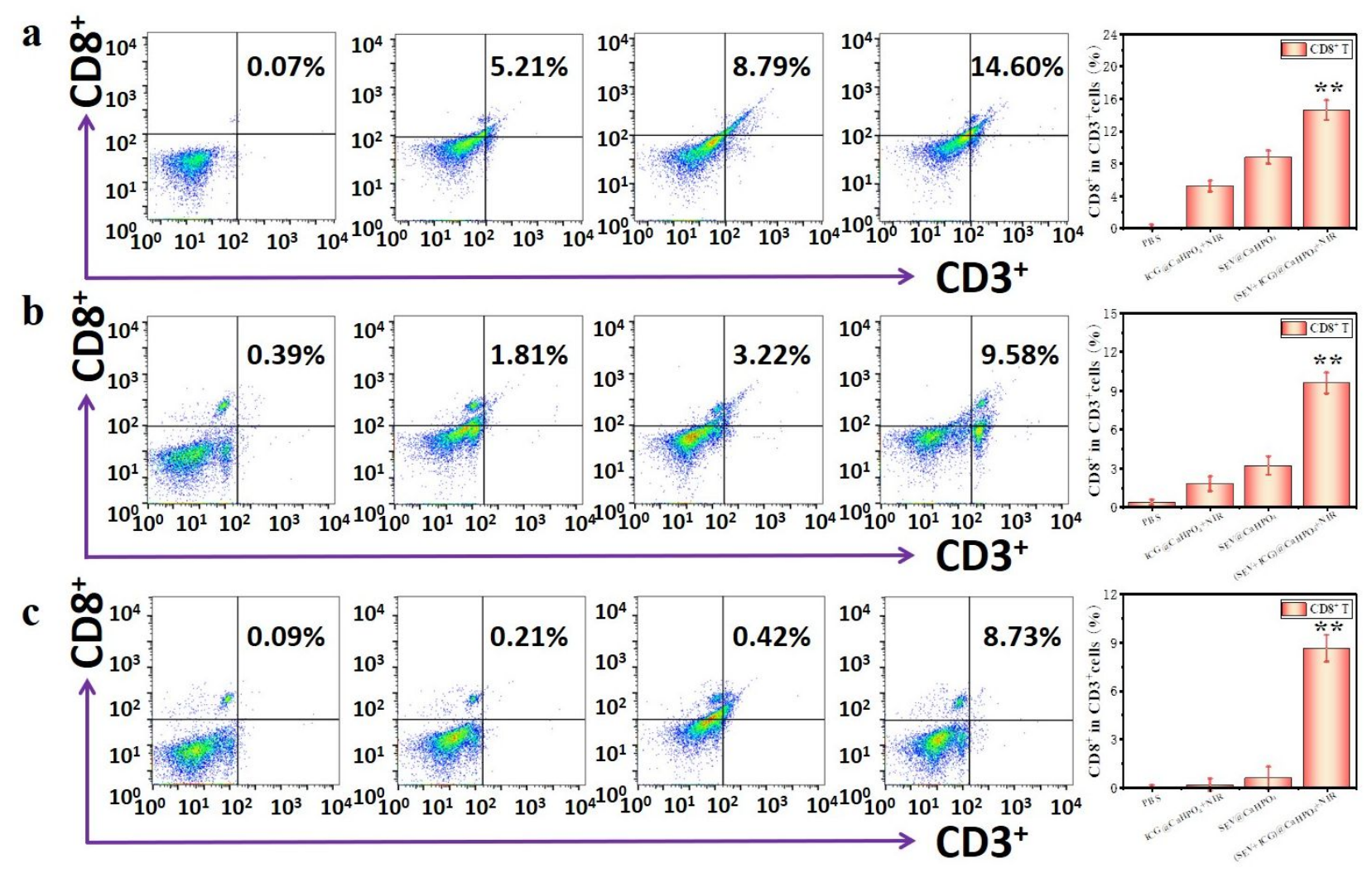

Figure S26. Flow cytometry for quantitative detection of $\mathrm{CD} 8^{+} \mathrm{T}$ cells throughout the body. a) lymph gland, b) spleen and c) blood. 

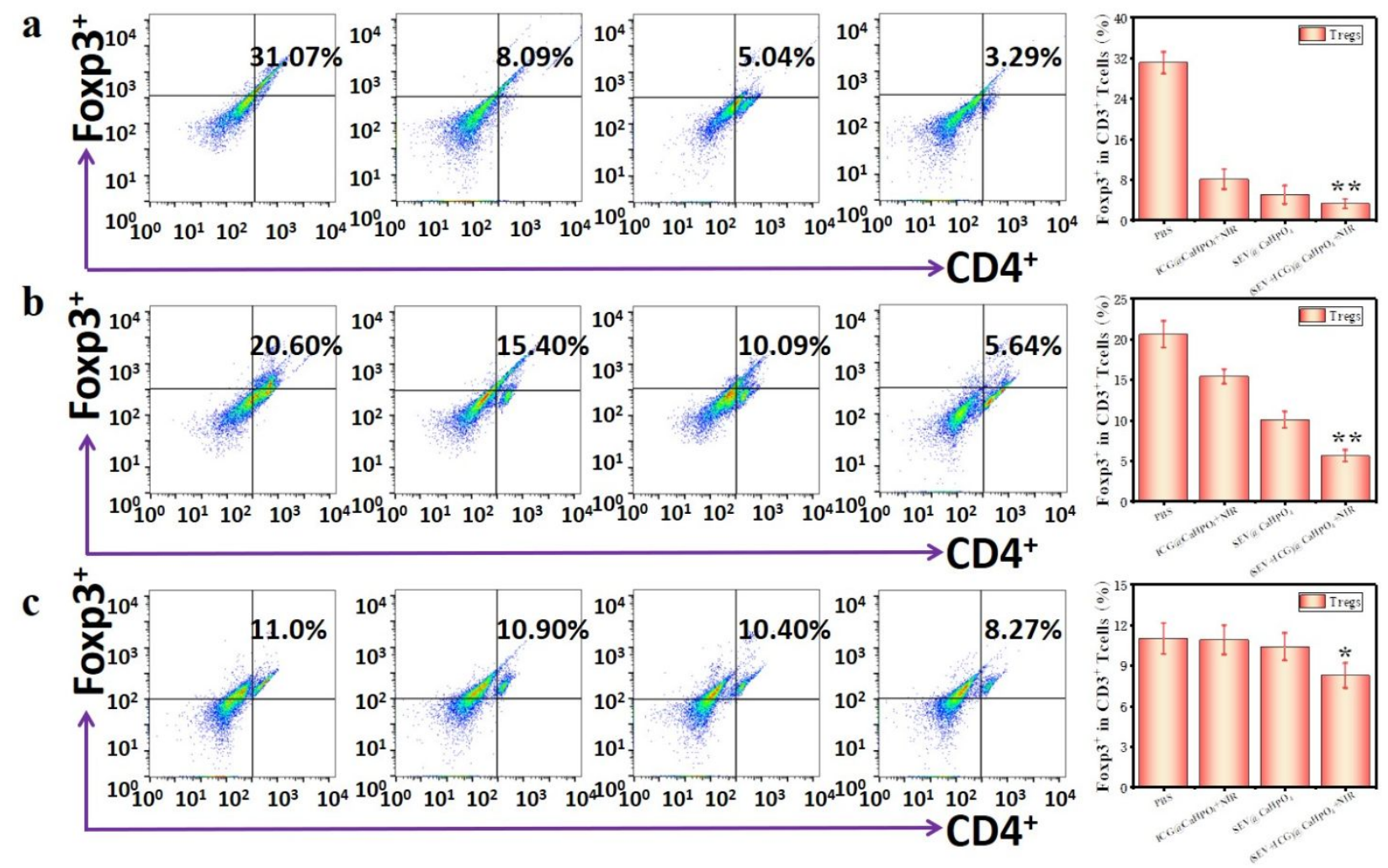

Figure S27. Flow cytometry for quantitative detection of Tregs $\left(\mathrm{CD} 4^{+} \mathrm{Foxp}^{+}\right)$cells throughout the body. a) lymph gland, b) spleen and c) blood. 

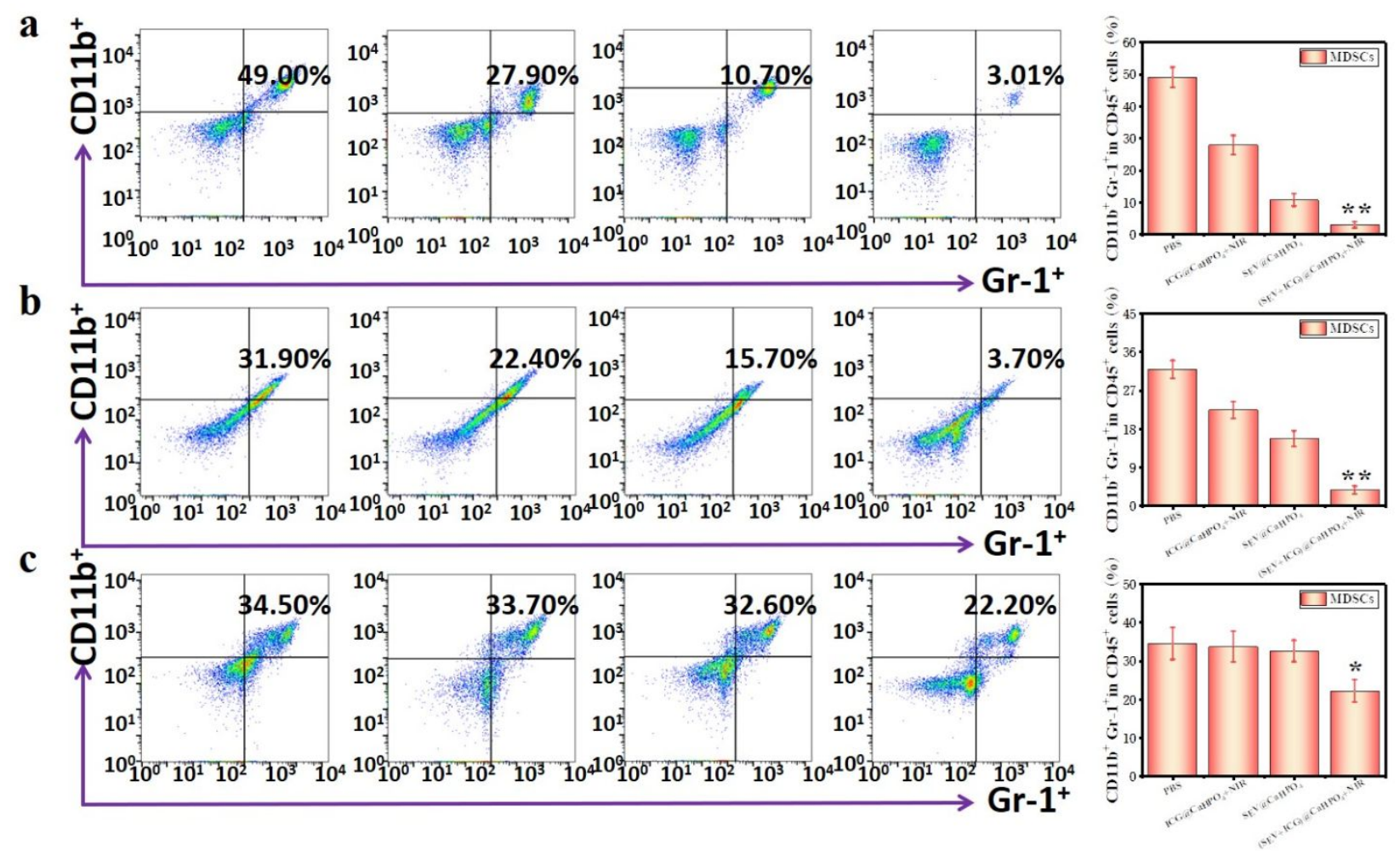

Figure S28. Flow cytometry for quantitative detection of MDSCs $\left(\mathrm{CD} 11 \mathrm{~b}^{+} \mathrm{Gr}-1^{+}\right)$cells throughout the body. a) lymph gland, b) spleen and c) blood. 

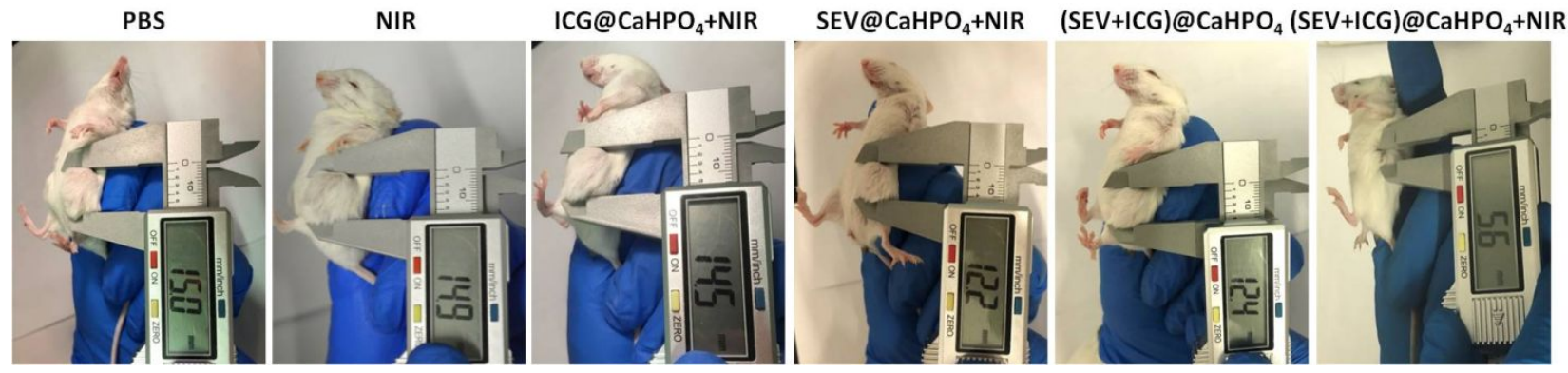

Figure S29. Macroscopic photographs of distal tumor changes in 4T1-bearing mice after different sample treatments. 
PBS

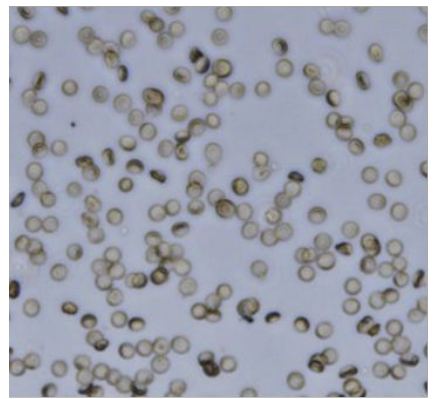

(SEV+ICG)@CaHPO

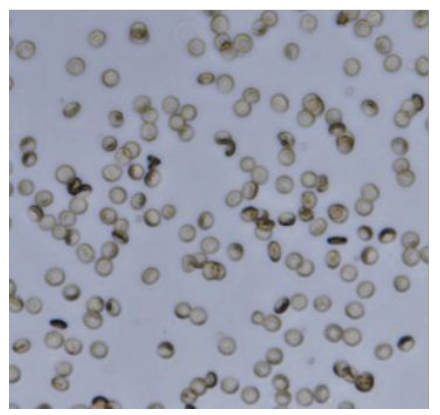

ICG@CaHPO

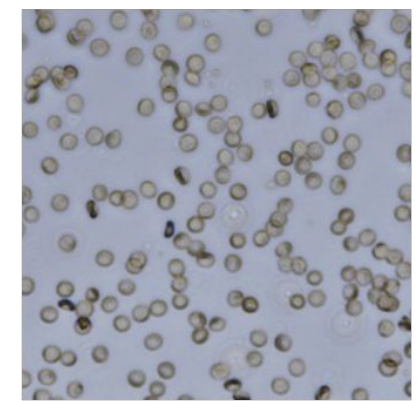

$(\mathrm{SEV}+\mathrm{ICG}) @ \mathrm{CaHPO}_{4}+\mathrm{NIR}$

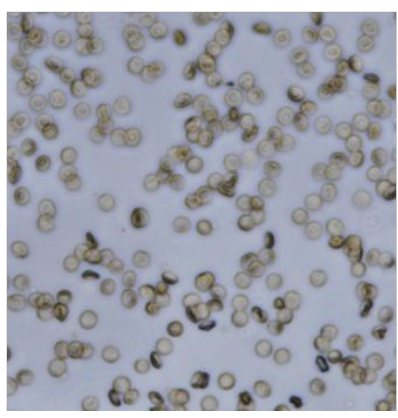

$\mathrm{SEV} @ \mathrm{CaHPO}_{4}$

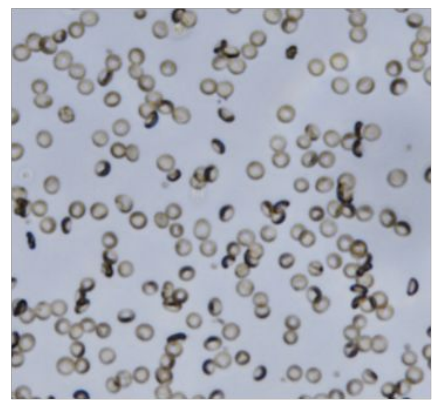

SEV

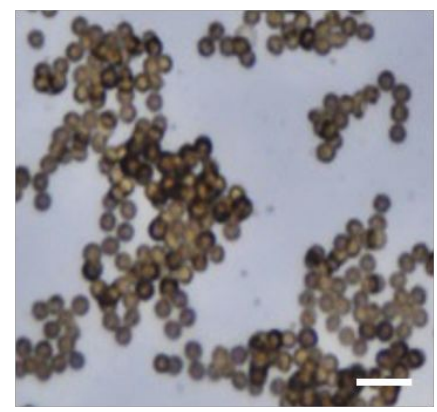

Figure S30. Evaluation of erythrocyte hemolysis in mice stimulated by Sendai virus before and after biomineralization. The scale bars were $100 \mu \mathrm{m}$. 


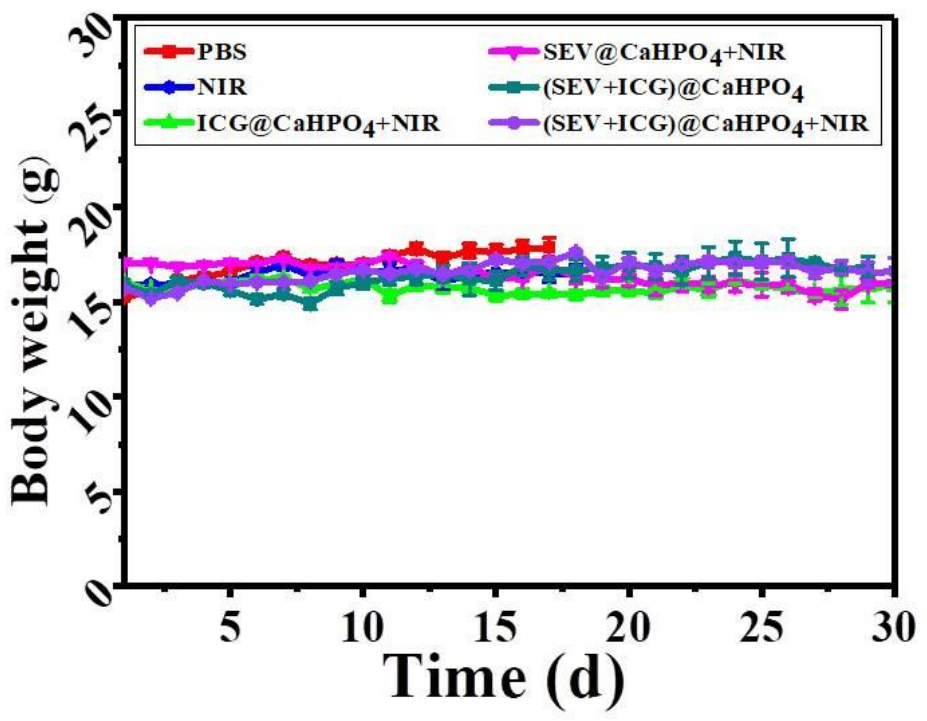

Figure S31. Changes in body weight of 4T1-bearing mice in different treatment groups. 


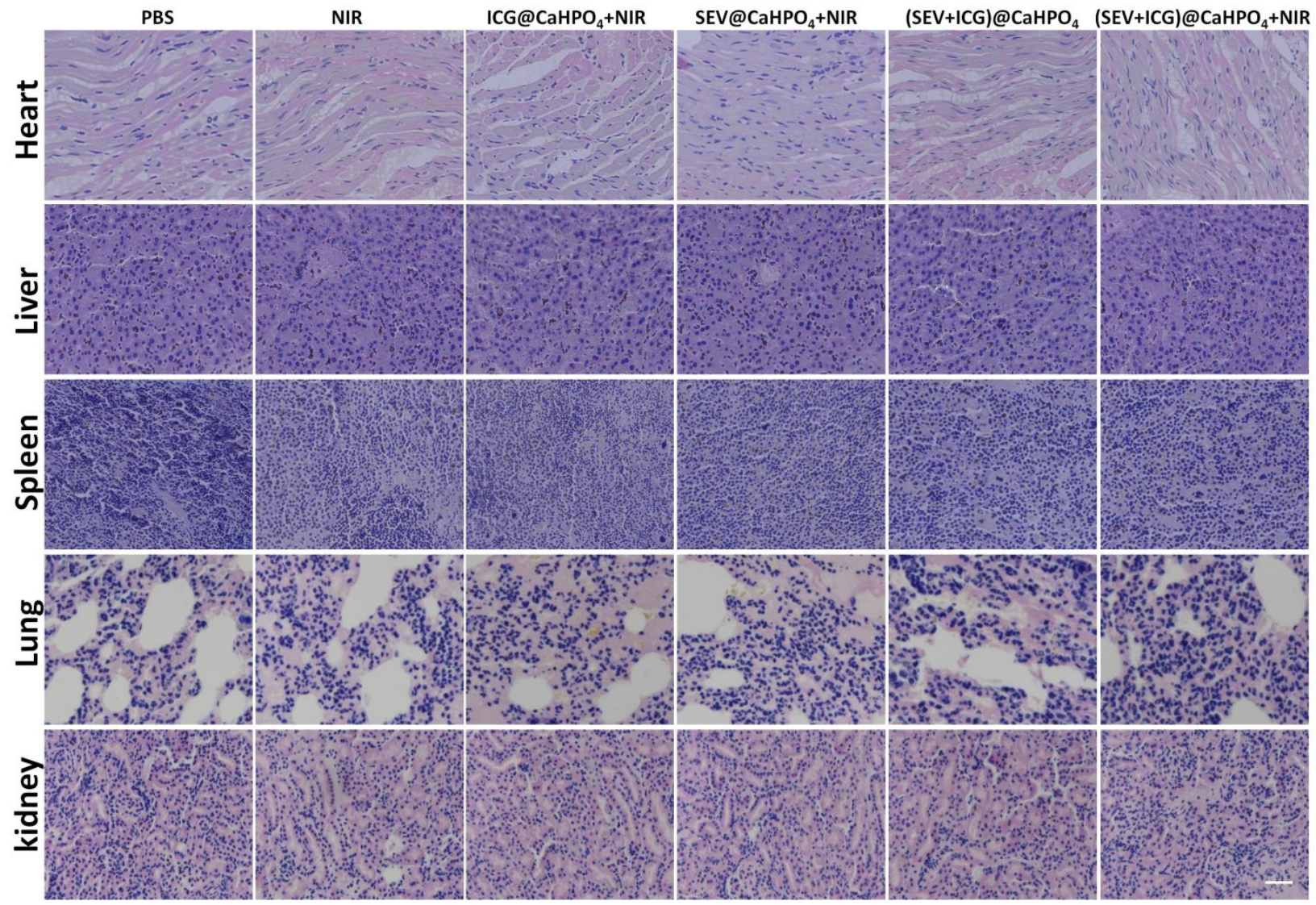

Figure S32. H\&E staining of the main organs of the 4T1-bearing mice after the end of the treatment in different experimental groups. The scale bars were $200 \mu \mathrm{m}$. 

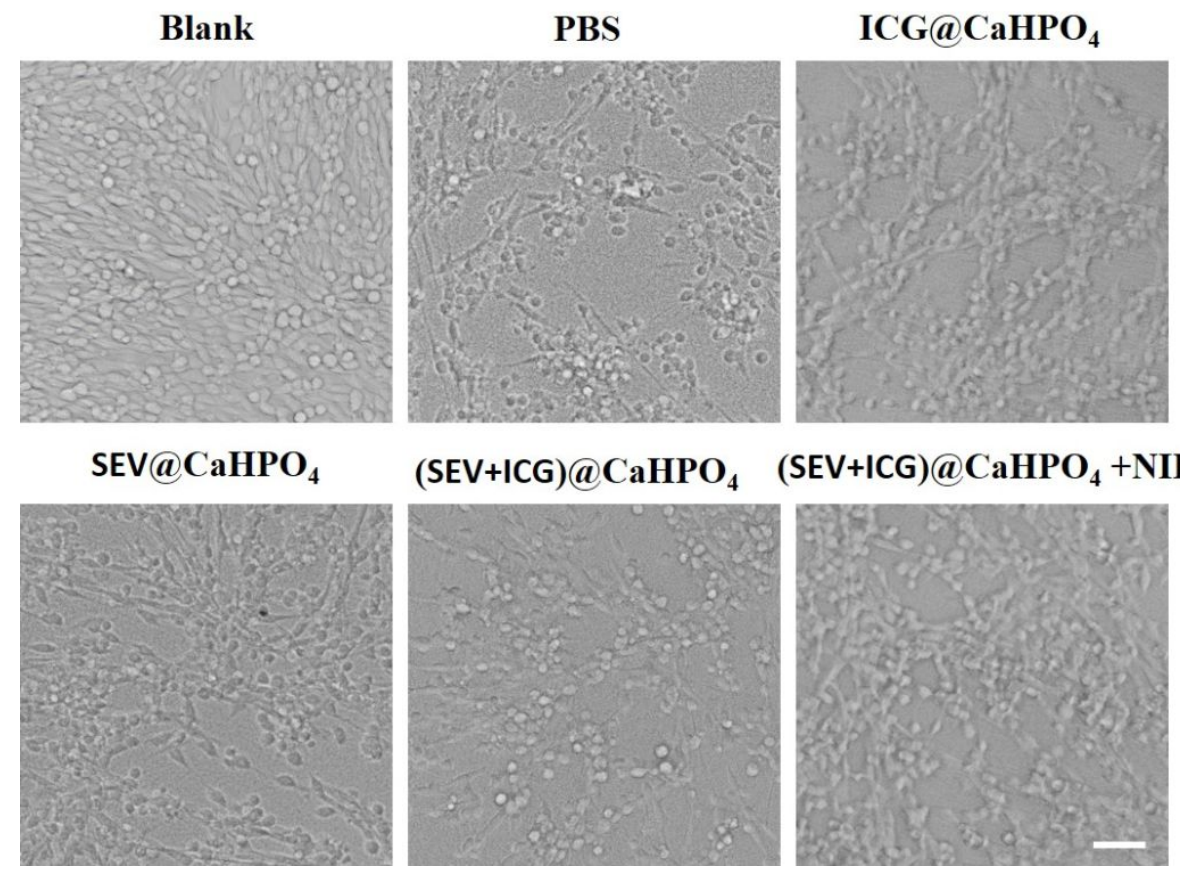

$(\mathrm{SEV}+\mathrm{ICG}) @ \mathrm{CaHPO}_{4} \quad(\mathrm{SEV}+\mathrm{ICG}) @ \mathrm{CaHPO}_{4}+\mathrm{NIR}$
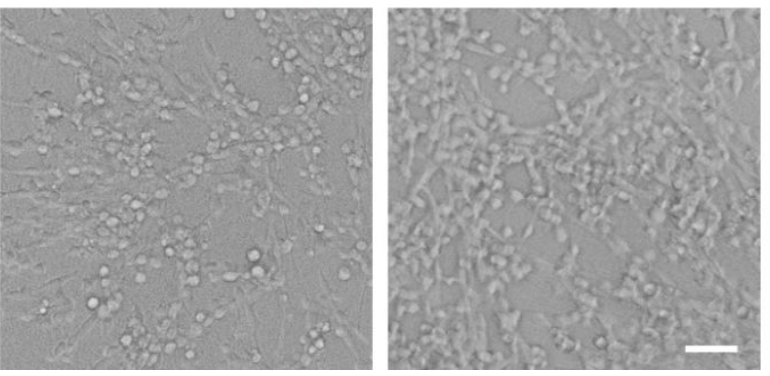

Figure S33. The virus neutralization test for detecting the production of antibodies against the Sendai virus antigens in C6 cells. The scale bars were $100 \mu \mathrm{m}$. 


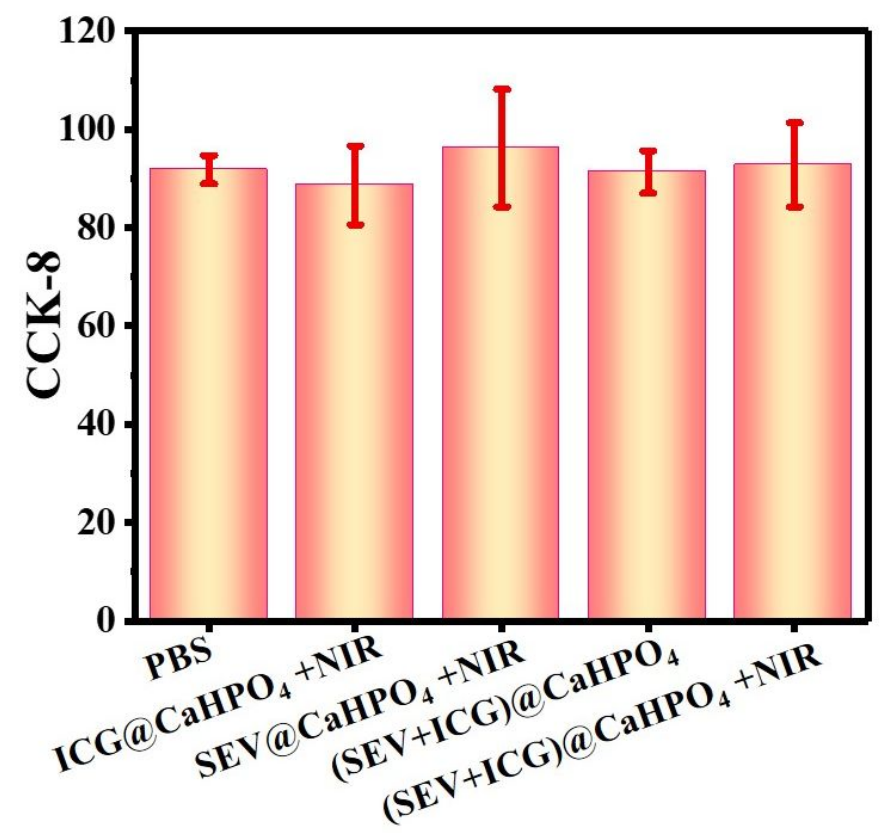

Figure S34. At the end of the treatment, lymphocytes in the lymph nodes of mice were collected, and the proliferation of lymphocytes was detected under the stimulation of Sendai virus. 